\title{
Effects of Renewable Diesel Exhaust on Lung Function and Self-rated Symptoms for Healthy Volunteers in a Human Chamber Exposure Study
}

Louise Gren ( $\square$ louise.gren@design.lth.se )

Lund University: Lunds Universitet https://orcid.org/0000-0002-1198-4995

Katrin Dierschke

Lund University: Lunds Universitet

Fredrik Mattsson

Lund University: Lunds Universitet

Eva Assarsson

Lund University: Lunds Universitet

Annette M. Krais

Lund University: Lunds Universitet

Monica Kåredal

Lund University: Lunds Universitet

Karin Lovén

Lund University: Lunds Universitet

Jakob Löndahl

Lund University: Lunds Universitet

Joakim Pagels

Lund University: Lunds Universitet

Bo Strandberg

Lund University: Lunds Universitet

Martin Tunér

Lund University: Lunds Universitet

Yiyi Xu

University of Gothenburg: Goteborgs Universitet

Per Wollmer

Lund University: Lunds Universitet

Maria Albin

Karolinska Institute: Karolinska Institutet

Jörn Nielsen

Lund University: Lunds Universitet

Anders Gudmundsson 
Lund University: Lunds Universitet

\section{Aneta Wierzbicka}

Lund University: Lunds Universitet

\section{Research}

Keywords: hydrotreated vegetable oil (HVO), inhalation, aerosol, peak nasal inspiratory flow (PNIF), peak expiratory flow (PEF), forced oscillation technique (FOT), symptoms, pulmonary function, non-road vehicles, occupational exposure limits (OELs)

Posted Date: April 16th, 2021

DOl: https://doi.org/10.21203/rs.3.rs-405371/v1

License: (c) (1) This work is licensed under a Creative Commons Attribution 4.0 International License. Read Full License 


\section{Effects of renewable diesel exhaust on lung function and self-rated}

\section{2 symptoms for healthy volunteers in a human chamber exposure study}

4 Louise Gren ${ }^{1,2}$, Katrin Dierschke3, Fredrik Mattsson ${ }^{1}$, Eva Assarsson³, Annette M. Krais³, Monica

5 Kåredal ${ }^{2,3}$, Karin Lovén ${ }^{1,2}$, Jakob Löndahl1,2, Joakim Pagels ${ }^{1,2}$, Bo Strandberg33, Martin Tunér4, Yiyi

6 Xu5, Per Wollmer ${ }^{6}$, Maria Albin 3,7, Jörn Nielsen33, Anders Gudmundsson ${ }^{1,2}$, Aneta Wierzbicka ${ }^{1^{*}}$

8 Keywords: hydrotreated vegetable oil (HVO), inhalation, aerosol, peak nasal inspiratory flow

9 (PNIF), peak expiratory flow (PEF), forced oscillation technique (FOT), symptoms, pulmonary

10 function, non-road vehicles, occupational exposure limits (OELs)

12 Ergonomics and Aerosol Technology, Lund University, Lund, SE-221 oo, Sweden

13 2Lund University, NanoLund, SE-221 oo Lund, Sweden

14 3Division of Occupational and Environmental Medicine, Lund University, Lund, SE-221 85,

15 Sweden

16 4Division of Combustion Engines, Lund University, Lund, SE-221 oo, Sweden

17 5School of Public Health and Community Medicine, Institute of Medicine, University of

18 Gothenburg, Sweden

19 'Department of Translational Medicine, Lund University, Sweden

207 Unit of Occupational Medicine, Institute of Environmental Medicine, Karolinska Institute,

21 Stockholm, Sweden

$23 \quad{ }^{*}$ Corresponding author (published version): aneta.wierzbicka@design.lth.se

24 Corresponding author during revision process: Louise Gren, louise.gren@design.lth.se 
Abstract

27 Background: Diesel engine exhaust causes adverse health effects. Meanwhile, the impact of 28 renewable diesel exhaust on human health is less known. In this study, nasal patency, pulmonary 29 function, and self-rated symptoms were assessed in 19 healthy volunteers after two separate 330 hour exposures to renewable diesel (hydrotreated vegetable oil [HVO]) exhaust, and exposure to 31 filtered air (FA) for comparison. The HVO exposures were generated with two modern non-road 32 vehicles (2019) having either: 1) no aftertreatment system (HVOPM+NOx), or 2) an aftertreatment 33 system containing a diesel oxidation catalyst and a diesel particulate filter ( $\left.\mathrm{HVO}_{\mathrm{NO}}\right)$. The exposure 34 concentrations complied with current EU occupational exposure limits (OELs) of $\mathrm{NO}, \mathrm{NO}_{2}$, 35 formaldehyde, polycyclic aromatic hydrocarbons (PAHs), and future OELs of elemental carbon 36 (EC) from 2023.

Results: Exposure to $\mathrm{HVO}_{\mathrm{PM}+\mathrm{NOx}}$ consisted of PM1 $\left(\approx 90 \mu \mathrm{g} \mathrm{m}^{-3}, 54 \mu \mathrm{g} \mathrm{m}^{-3} \mathrm{EC}\right)$ and $\mathrm{NO}_{\mathrm{x}}\left(\mathrm{NO}_{3.4}\right.$ $\left.\mathrm{ppm}, \mathrm{NO}_{2} 0.6 \mathrm{ppm}\right)$. The average total respiratory tract deposition of PM1 was $27 \mu \mathrm{g} \mathrm{h}^{-1}$. The deposition fraction of HVO PM1 was 40-50\% higher compared to diesel exhaust PM1 from an older vehicle, due to smaller particle sizes of the $\mathrm{HVO}_{\mathrm{PM}+\mathrm{NOx}}$ exhaust. Exposure to $\mathrm{HVO}_{\mathrm{NOx}}$ consisted mainly of $\mathrm{NO}_{\mathrm{x}}\left(\mathrm{NO} 2.0 \mathrm{ppm}, \mathrm{NO}_{2} 0.7 \mathrm{ppm}\right)$ with low level of PM1 $(\sim 1 \mu \mathrm{g} \mathrm{m}-3)$. Compared to filtered air, exposure to $\mathrm{HVO}_{\mathrm{PM}+\mathrm{NO}}$ and $\mathrm{HVO}_{\mathrm{NOx}}$ caused higher incidence of self-reported symptoms (78\%, 63\%, respectively, vs. $28 \%$ for FA, p<0.03). Especially, exposure to $\mathrm{HVO}_{\mathrm{PM}+\mathrm{NOx}}$ showed $40-50 \%$ higher eye and throat irritation symptoms. Compared to filtered air, a decrement in nasal patency was found for the $\mathrm{HVO}_{\mathrm{NO}}$ exposures $\left(-18.1,95 \% \mathrm{CI}:-27.3\right.$ to $\left.-8.8 \mathrm{~L} \mathrm{~min}^{-1}\right)$, and for the $\mathrm{HVO}_{\mathrm{PM}+\mathrm{NOx}}\left(-7.4(-15.6\right.$ to 0.8$\left.) \mathrm{L} \mathrm{min}^{-1}\right)$. Overall, no change was indicated in the pulmonary function tests (spirometry, peak expiratory flow, forced oscillation technique), except a slight increase in $\mathrm{FEV}_{1} / \mathrm{FVC}$ after exposure to $\mathrm{HVO}_{\mathrm{NOx}}$. 
51 Conclusion: Short-term exposure to HVO exhaust below the EU OELs did not cause severe

52 pulmonary function changes in healthy subjects. However, an increase in self-rated mild irritation

53 symptoms, and mild decrease in nasal patency after two HVO exposures may indicate irritative

54 effects from exposure to HVO exhaust from modern non-road vehicles below future OELs.

55

56

57

58

59 
61 Exposure to petroleum diesel engine exhaust is known to cause adverse health effects (1-4), and

62 since 2012, diesel engine exhaust has been classified as carcinogenic to humans (5). Several human exposure studies have linked diesel exposure to acute health effects, among them short-term 64 reduced lung function (6-10), airway inflammatory responses (10-13), irritation symptoms $65(6,7,14,15)$, and cardiovascular effects (16-18). Stricter emission standards in recent years and 66 improved emission reduction techniques have reduced the particle and gas emissions from modern diesel vehicles. At the same time the use of renewable diesel fuels has increased rapidly in an effort to reduce net $\mathrm{CO}_{2}$ emissions. These fuels, such as hydrotreated vegetable oil (HVO) and biodiesel of fatty acid methyl ester (FAME) types, decrease the particulate matter (PM) emissions compared to petroleum diesel (19-22). However, compared to petroleum diesel the toxicity of these emissions is less evaluated. Only a few controlled human exposure studies of FAME type 72 fuels exist $(8,23)$, while there are to the best of the authors' knowledge, no such studies on HVO.

73 Compared to FAME fuels, HVO is the preferred fuel for full substitution (pure biodiesel, B100) of 74 petroleum diesel in non-modified diesel engines due to its greater engine compatibility. With all

75 the known adverse effects of petroleum diesel exhaust from older vehicles, the research focus 76 should be directed to investigate the health effects of realistic exposure concentrations from modern renewable fuels used in vehicles with different exhaust aftertreatment systems.

The exhaust emissions of $\mathrm{HVO}$ are, on the one hand, similar to petroleum diesel as the combustion generates carbonaceous PM ("soot”), nitrogen oxides $\left(\mathrm{NO}_{\mathrm{x}}\right)$, polycyclic aromatic hydrocarbons (PAHs), etc., but on the other hand, they are different in terms of concentration, particle size and chemical composition (24-27). For example, HVO can decrease the PM emission by $20-50 \%$ in comparison to petroleum diesel $(20,21)$. It should be noted that similar to diesel, HVO contains no oxygen or feedstock-derived impurities (e.g., metals) that influence emission characteristics, as do FAME-type biodiesels. The aerosol emission characteristics thus differ for HVO and FAME 
compared to petroleum diesel $(22,28)$. The solid PM fraction of the exhaust from diesel and HVO is dominated by soot, which can be measured thermo-optically as elemental carbon (EC). A new EU occupational exposure limit (OEL) for diesel engine exhaust, measured as EC, of $50 \mu \mathrm{g} \mathrm{m}^{-3}$ (29) will be implemented in 2023 to reduce the exposure of the 3.6 million workers within the member states (30). Because estimates of the life-time mortality risk from occupational exposure to diesel for cancer alone (not including myocardial infarction or COPD) indicate that exposure levels need to be kept extremely low (Vermeulen et al. 2014), it is of key importance to identify potential adverse effects of the substitutes. As the substitution of petroleum diesel by renewable diesel is increasing, a considerable number of people will be exposed to its exhaust. It is hence of interest to understand the potential health effects of exhaust exposure from engines running on HVO, while complying with the future OELs.

Exhaust aftertreatment systems are used in diesel vehicles in order to reduce the environmental and health hazardous emissions of PM (both mass and number concentration), $\mathrm{CO}, \mathrm{NO}_{\mathrm{x}}$, and organic compounds such as PAHs. An aftertreatment system can, for example, contain a diesel oxidation catalyst (DOC) that oxidizes $\mathrm{CO}$ and organic compounds (31,32), and a diesel particle filter (DPF) that oxidizes soot particles which removes significant amounts of PM (33). Hence use of aftertreatment systems should reduce exposure to such emissions and their associated health effects. However, a recent review assessing the effects of DPFs' use on health impacts in occupational settings did not present conclusive results (34). It is thus of interest to investigate the health impact from vehicles with different degrees of emission reduction technology.

Due to improved engine operation, modern diesel engines with or without aftertreatment systems generally emit lower concentrations of pollutants (35) and reduce exhaust particle mass and size (36). Particle characteristics such as size and morphology are of key importance in considering possible health effects, as these characteristics determine where in the lungs the particles will 
112 deposit. The deposition pattern in the lung depends on multiple aerosol characteristics and not

113 solely on the respirable PM mass concentration (37).

115 In the present study we investigate the human health effects from exposure to exhaust from two 116 modern non-road vehicles (wheel loaders). Due to their engine capacity, they fall under different

117 emission standards and were equipped with 1) no external aftertreatment device, or 2) a DOC in 118 combination with a DPF. The different emissions aftertreatment allowed for a comparison of the 119 exposure to $\mathrm{NO}_{\mathrm{x}}$ from diesel engines with and without a particulate fraction and other gaseous

120 pollutants. We aimed to evaluate self-rated symptoms, nasal patency, and pulmonary function

121 after exposure to HVO exhaust from modern non-road vehicles that complied with the EU OELs.

122 Additionally, we investigated the lung deposition of HVO exhaust particles with the deposition of 123 petroleum diesel from an older light-duty vehicle presented by Wierzbicka et al. in a previous 124 study (15). 


\section{Results}

Main findings

We compared the effects of exposure to exhaust from hydrotreated vegetable oil (HVO) (a renewable diesel fuel) with filtered air (FA). The vehicle without an external aftertreatment system $\left(\mathrm{HVO}_{\mathrm{PM}+\mathrm{NOx}}\right)$ generated emissions of $\mathrm{PM}, \mathrm{NO}_{\mathrm{x}}$ and organic compounds. The vehicle with an external aftertreatment consisting of a DOC and DPF ( $\left.\mathrm{HVO}_{\mathrm{NO}}\right)$ emitted $\mathrm{NO}_{\mathrm{x}}$ with only negligible concentrations of particles and measured organic components (hereafter referred to only $\mathrm{NO}_{\mathrm{x}}$ ). The two exposures to HVO caused mild self-rated irritations symptoms. 44\% reported eye irritation symptoms during the $\mathrm{HVO}_{\mathrm{PM}+\mathrm{NOx}}$ exposure. The number of volunteers who reported throat irritation symptoms was a factor 4.5 and 4 higher for $\mathrm{HVO}_{\mathrm{PM}+\mathrm{NOx}}$ and $\mathrm{HVO}_{\mathrm{NOx}}$ respectively, compared to FA. In comparison to FA exposure, nasal obstruction (lower PNIF) occurred for the $\mathrm{HVO}_{\mathrm{NO}}$ exposure. In the first of the following two sections we describe the exposure aerosol characteristics and the HVO exhaust particle deposition in the airways in relation to diesel exhaust particles. In the second, we describe the health effects in terms of self-rated symptoms and airway function.

\section{Exposure and lung deposition}

\section{Exposure aerosol characteristics}

A summary of the average aerosol exposure concentrations and characteristics are presented in Table 1. The average aerosol exposure characteristics during the three exposure scenarios are presented in Fig. 1. The average PM1 concentration during the $\mathrm{HVO}_{\mathrm{PM}+\mathrm{NO}}$ exposures was $93 \pm 13 \mu \mathrm{g}$ $\mathrm{m}^{-3}$ and the average particle number (PN) concentration was $3.0 \cdot 10^{5} \pm 0.3 \cdot 10^{5} \mathrm{~cm}^{-3}$ (Table 1). In contrast, during $\mathrm{HVO}_{\mathrm{NOx}}$ and FA exposures, the average exposure concentrations of PM1 were $\sim 1$ $\mu \mathrm{g} \mathrm{m}^{-3}$ and $\mathrm{PN}<100 \mathrm{~cm}^{-3}$ (Table 1). For $\mathrm{HVO}_{\mathrm{PM}+\mathrm{NO}}$, the elemental carbon (EC) fraction of total carbon was $66 \pm 3 \%$ corresponding to an average EC concentration of $54 \pm 6 \mu \mathrm{g} \mathrm{m}^{-3}$ (Table 1). The 
two vehicles were operated in a similar load/idle sequence, which is seen as increasing (during load) and decreasing (during idle) PM1 mass (Fig. 1a) and NO concentrations during HVOPM+NOx exposure, and increasing/decreasing $\mathrm{NO}_{2}$ levels for the $\mathrm{HVO}_{\mathrm{NOx}}$ exposures (Fig. 1b).

The $\mathrm{NO}$ and $\mathrm{NO}_{2}$ concentrations were comparable for the two HVO exposures (no vehicle had external $\mathrm{NO}_{\mathrm{x}}$ removal devices, such as selective catalytic reduction [SCR]) and on average below the 8-hour OELs. During the $\mathrm{HVO}_{\mathrm{NOx}}$ exposure, the average $\mathrm{NO}_{2}$ was slightly higher and the average NO lower compared to $\mathrm{HVO}_{\mathrm{PM}+\mathrm{NOx}}$ (Table 1). The variations in $\mathrm{NO}$ and $\mathrm{NO}_{2}$ from the load/idle operation as described above can be seen in Fig. 1b. In addition, NO increased rapidly after the cold start at the start of the $\mathrm{HVO}_{\mathrm{NO}}$ exposure and decreased shortly thereafter when the diesel oxidation catalyst (DOC) of the vehicle has reached the operating temperature and started to convert $\mathrm{NO}$ to $\mathrm{NO}_{2}$ more efficiently.

During the $\mathrm{HVO}_{\mathrm{PM}+\mathrm{NO}}$ exposure scenario (with the vehicle without aftertreatment) gas-phase organic compounds were quantified, but below the OELs, among them PAHs $\left(889 \pm 53 \mathrm{ng} \mathrm{m}^{-3}\right)$, BTEX $\left(11.6 \pm 3.0 \mu \mathrm{g} \mathrm{m}^{-3}\right)$, and formaldehyde $\left(51 \pm 6 \mu \mathrm{g} \mathrm{m}^{-3}\right)$. These emissions were low or below limit of detection (LOD) during the other exposure scenarios. Full PAH (33 native and alkylated, 10 oxyand 17 nitro-PAHs) and BTEX analyses are presented in Additional file B and C, respectively.

The particle number and mass size distribution of $\mathrm{HVO}_{\mathrm{PM}+\mathrm{NOx}}$, together with the effective density of the soot agglomerates, are shown in Fig. 2a. The effective density decreased with increasing mobility size, as the soot agglomerates became more open in their structure, and the diesel soot power law function described by Park et al. (38) could be fitted to the experimental data (Fig. 2a). The mass mobility exponent $\left(\mathrm{D}_{\mathrm{fm}}\right)$ was on average 2.3 (where 3 corresponds to perfect spheres). An example of the soot agglomerates generated during the HVOPM+NOx exposure is imaged by 
transmission electron microscopy (TEM) in Fig. 2b. The average primary particle diameter of the soot agglomerates of $\mathrm{HVO}_{\mathrm{PM}+\mathrm{NOx}}$ was $24.5 \pm 7.3 \mathrm{~nm}$ and an example is marked in Fig. $2 \mathrm{~b}$.

180 Table 1. Summary of the average aerosol concentrations and characteristics during exposures in 181 the chamber.

\begin{tabular}{|c|c|c|c|c|}
\hline & & $\mathrm{HVO}_{\mathrm{PM}+\mathrm{NOX}}$ & HVONOX & FA \\
\hline \multirow[t]{15}{*}{ Particle phase } & PM1 ( $\left.\mu \mathrm{g} \mathrm{m}^{-3}\right)$ (Gravimetric) & $93 \pm 13$ & $\overline{\sim 1^{a}}$ & $\sim 1^{\text {a }}$ \\
\hline & PM1 Total Carbon $\left(\mathrm{TC}, \mu \mathrm{g} \mathrm{m}^{-3}\right)$ & $82 \pm 10$ & $<1$ & $<1$ \\
\hline & EC/TC $(\%)$ & $66 \pm 3$ & - & - \\
\hline & OC/TC (\%) & $34 \pm 3$ & - & - \\
\hline & $\begin{array}{l}\text { PM1 }\left(\mu \mathrm{g} / \mathrm{m}^{3}\right) \quad(\text { SMPS and } \\
\left.\rho_{\text {eff }}\right)\end{array}$ & $81 \pm 9$ & $0.0 \pm 0.0$ & $0.5 \pm 0.5$ \\
\hline & 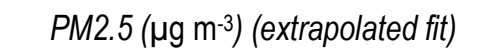 & $81 \pm 9$ & - & - \\
\hline & $\mathrm{GMD}_{\text {mass }}(\mathrm{nm})$ & 114 & - & - \\
\hline & $\operatorname{GSD}_{\text {mass }}(\mathrm{nm})$ & 1.48 & - & - \\
\hline & $\mathrm{PN}\left(\mathrm{cm}^{-3}\right)$ & $3.0 \cdot 10^{5}$ & $9.0 \cdot 10^{1}$ & $7.1 \cdot 10^{1}$ \\
\hline & PN std. dev & $0.3 \cdot 10^{5}$ & $4.1 \cdot 10^{1}$ & $4.3 \cdot 10^{1}$ \\
\hline & GMDpN (nm) & 71 & 47.2 & - \\
\hline & GSDpN $(n m)$ & 1.64 & 1.46 & - \\
\hline & Surface area $\left(\mathrm{cm}^{-2} \mathrm{~cm}^{-3}\right)$ & $9.5 \cdot 10^{-5}$ & - & - \\
\hline & $\begin{array}{l}\text { Surface area std. dev }\left(\mathrm{cm}^{-2} \mathrm{~cm}^{-}\right. \\
\text {3) }\end{array}$ & $1.4 \cdot 10^{-5}$ & - & - \\
\hline & Particle phase PAHs ${ }^{\mathrm{b}}\left(\mathrm{ng} \mathrm{m}^{-3}\right)$ & $43 \pm 3$ & $0.3 \pm 0.7$ & $0.2 \pm 0.2$ \\
\hline \multirow[t]{8}{*}{ Gas phase } & Gas phase $\mathrm{PAHs}^{\mathrm{b}}\left(\mathrm{ng} \mathrm{m}^{-3}\right)$ & $850 \pm 48$ & $97 \pm 11$ & $116 \pm 29$ \\
\hline & Formaldehyde $\left(\mu \mathrm{g} \mathrm{m}^{-3}\right)$ & $51 \pm 6$ & $<8$ & $<8$ \\
\hline & Sum BTEX $\left(\mu \mathrm{g} \mathrm{m}^{-3}\right)$ & $7.9 \pm 2.5$ & $1.7 \pm 0.3$ & $1.3 \pm 0.1$ \\
\hline & VOCs (ppb) & $333 \pm 69$ & $11 \pm 5$ & $<10$ \\
\hline & NO (ppm) & $3.4 \pm 0.1$ & $2.0 \pm 0.1$ & $<0.001$ \\
\hline & $\mathrm{NO}_{2}(\mathrm{ppm})$ & $0.57 \pm 0.04$ & $0.70 \pm 0.04$ & $<0.001$ \\
\hline & $\mathrm{NO} / \mathrm{NO}_{2}$ ratio & 5.7 & 2.9 & - \\
\hline & $\mathrm{CO}_{2}(\mathrm{ppm})$ & $1344 \pm 143$ & $1332 \pm 135$ & $813 \pm 140$ \\
\hline
\end{tabular}

All values are the average of all exposures $(n=5-6)$ of a given type with \pm 1 std. dev. Full compound analyses of PAHs and BTEX are found in Additional file B and C, respectively.

a There were large uncertainties in the gravimetric mass analysis at low/no mass concentrations. The mass concentrations were in the range of the blank filters $(-1 \pm 3 \mu \mathrm{g})$.

${ }^{\mathrm{b}} 33$ native and alkylated, 10 oxy- and 17 nitro-PAHs were included in the analysis. 
The calculated average inhaled deposited particle mass from nasal breathing during the $\mathrm{HVO}_{\mathrm{PM}+\mathrm{NOx}}$ exposure in the tracheobronchial and alveolar regions, from airway generation 1 to 24 ,

A comparison is presented in Fig. $3 \mathrm{~b}$ of the total deposited particle mass doses in the different airway regions in the current study and in a previous petroleum diesel exposure study $(6,15)$. The comparison was made for both the original diesel mass concentration in the past study ( $276 \mu \mathrm{g} \mathrm{m}^{-}$ 3, light grey bars) and with the same mass concentration as in this study (93 $\mu \mathrm{g} \mathrm{m}^{-3}$, dark grey bars) using the original aerosol characteristics of the petroleum diesel (MMD $195 \mathrm{~nm}$, GSD 1.65). The deposited mass of the diesel aerosol was higher in comparison to $\mathrm{HVO}_{\mathrm{PM}+\mathrm{NO} \text {, }}$, but lower when using the same exposure mass concentrations. The deposited fractions of the HVOPM+NOx aerosol mass (i.e., the fraction of the deposited mass compared to the total inhaled mass concentration) were around 40-50\% higher compared to petroleum diesel in the tracheobronchial and alveolar regions. The average accumulated deposited dose in the respiratory tract was $82 \mu \mathrm{g}$ for HVOPM+NOx, corresponding to an hourly average of $27 \mu \mathrm{g} \mathrm{h} \mathrm{h}^{-1}$.

The inhaled deposited dose depends on multiple lung parameters (FRC, tidal volume, breathing pattern, etc.). For additional comparison with petroleum diesel, the same deposition model (oral breathing, [39]) was used as in Wierzbicka et al. (15). Table 2 presents the deposited HVOPM+NOx particle dose expressed as mass, number and surface area compared to the petroleum diesel exposure (using the original exposure concentrations). Please note the three times higher particle mass concentration in the case of diesel in comparison to HVO when looking at values of deposited 
dose by mass. The mass (and surface area) deposition fraction was a factor 1.5 higher for $\mathrm{HVO}_{\mathrm{PM}+\mathrm{NOx}}$ than diesel. Additionally, the deposited dose in terms of particle number was a factor 1.2 higher for $\mathrm{HVO}_{\mathrm{PM}+\mathrm{NO}}$. As the particle number concentration was higher for $\mathrm{HVO}_{\mathrm{PM}+\mathrm{NOx}}$, despite

213 the lower mass concentration, this led to a higher number of particles deposited in the lungs for 214 HVO compared to diesel. The deposited mass fractions differ slightly from the multiple-path 215 particle dosimetry (MPPD) model due to model characteristics, see Additional File D for a comparison of the deposition fraction depending on particle size for the two models.

Table 2. The average lung deposition (oral breathing) fractions of PM1 of $\mathrm{HVO}_{\mathrm{PM}+\mathrm{NOx}}$ and 219 petroleum diesel.

\begin{tabular}{|c|c|c|c|c|}
\hline & & HVO (PM1) & Diesel (PM1), Wierzbicka et al. 2014 & Unit \\
\hline \multicolumn{2}{|c|}{ Mass concentration $\left(\mu \mathrm{g} \mathrm{m}^{-3}\right)$} & $93 \pm 13$ & $276 \pm 56$ & \\
\hline \multicolumn{2}{|c|}{ Particle number concentration $\left(\mu \mathrm{g} \mathrm{m}^{-3}\right)$} & $3.0 \cdot 10^{5} \pm 0.3 \cdot 10^{5}$ & $3.9 \cdot 10^{5} \pm 0.5 \cdot 10^{5 *}$ & \\
\hline \multicolumn{2}{|c|}{ Surface area concentration $\left(\mu \mathrm{g} \mathrm{m}^{-3}\right)$} & $9.5 \cdot 10^{-5} \pm 1.4 \cdot 10^{-5}$ & $3.5 \cdot 10^{-4} \pm 0.7 \cdot 10^{-4}$ & \\
\hline \multirow[b]{2}{*}{ Mass } & Deposited fraction & $0.40 \pm 0.004$ & $0.27 \pm 0.01$ & \\
\hline & $\begin{array}{l}\text { Deposited dose during } 3 \mathrm{~h} \\
\text { exposure }\end{array}$ & $100.4 \pm 12.4$ & $118.5 \pm 21.6$ & $\mu g$ \\
\hline \multirow[b]{2}{*}{ Number } & Deposited fraction & $0.52 \pm 0.002$ & $0.45 \pm 0.03$ & \\
\hline & $\begin{array}{l}\text { Deposited dose during } 3 \mathrm{~h} \\
\text { exposure }\end{array}$ & $4.3 \cdot 10^{11} \pm 5.2 \cdot 10^{10}$ & $2.8 \cdot 10^{11} \pm 3.5 \cdot 10^{10}$ & Particles \\
\hline \multirow[b]{2}{*}{ Surface area } & Deposited fraction & $0.40 \pm 0.004$ & $0.27 \pm 0.01$ & \\
\hline & $\begin{array}{l}\text { Deposited dose during } 3 \mathrm{~h} \\
\text { exposure }\end{array}$ & $104.5 \pm 12.9$ & $151.9 \pm 27.7$ & $\mathrm{~cm}^{2}$ \\
\hline
\end{tabular}

The average lung deposition (oral breathing) fractions of PM1 of $\mathrm{HVO}_{\mathrm{PM}+\mathrm{NOx}}$ was calculated with the model presented by Rissler et al. (39) and compared to the calculated deposited doses of petroleum diesel from Wierzbicka et al. (15). The average mass, particle number and surface area concentrations of the respective exposures are given. All values are presented as mean \pm 1 std. dev.

*PMo.5

\section{$221 \quad$ Health effects}

\section{Self-rated symptoms}


Table 3: Descriptive table of the reported symptoms during each exposure scenario.

The number of volunteers reporting symptoms from eye, throat, nose, and chest during the exposures are shown in Table 3. Exposure to HVO (HVO ${ }_{\mathrm{PM}+\mathrm{NOx}}$ and $\left.\mathrm{HVO}_{\mathrm{NOx}}\right)$ caused significantly higher incidences of reported symptoms compared to FA (78\%, 63\% vs. 28\%, p<0.03 for both). The proportion of volunteers who reported throat irritation was a factor 4.5 and 4 higher for $\mathrm{HVO}_{\mathrm{PM}+\mathrm{NOx}}$ and $\mathrm{HVO}_{\mathrm{NOx}}$, respectively, compared to FA. The difference was statistically significant for $\mathrm{HVO}_{\mathrm{PM}+\mathrm{NOx}}(\mathrm{p}=0.011)$ and with borderline significance for $\mathrm{HVO}_{\mathrm{NOx}}(\mathrm{p}=0.062)$. The proportion of reported eye irritation symptoms was around a factor 2.5 higher for $\mathrm{HVO} \mathrm{PM}_{+\mathrm{NOx}}$ compared to FA with a borderline significance $(\mathrm{p}=0.07)$. No volunteers reported chest tightness during the FA exposure, while a few individuals did so during the $\mathrm{HVO}_{\mathrm{PM}+\mathrm{NOx}}$ and $\mathrm{HVO}_{\mathrm{NOx}}$, respectively.

However, it should be noted that the reported symptom scores were generally low (mostly below 10 in a 0-100 VAS) for all categories.

\begin{tabular}{|c|c|c|c|c|c|c|c|c|c|c|c|c|c|}
\hline & \multicolumn{3}{|c|}{ Any reported symptom } & \multicolumn{3}{|c|}{ Eye $^{a}$} & \multicolumn{3}{|c|}{ Throat $^{b}$} & \multicolumn{2}{|c|}{ Nose $^{c}$} & \multicolumn{2}{|c|}{ Chest $^{d}$} \\
\hline & $\begin{array}{l}\text { Yes/t } \\
\text { otal }\end{array}$ & $\%$ & $\begin{array}{c}P\left(\chi^{2}-\right. \\
\text { test })\end{array}$ & $\begin{array}{c}\text { Yes/t } \\
\text { otal }\end{array}$ & $\%$ & $\begin{array}{c}\mathrm{P}\left(\chi^{2}-\right. \\
\text { test })\end{array}$ & $\begin{array}{c}\text { Yes/t } \\
\text { otal }\end{array}$ & $\%$ & $\begin{array}{c}\mathrm{P}\left(\chi^{2}-\right. \\
\text { test })\end{array}$ & $\begin{array}{l}\text { Yes/t } \\
\text { otal }\end{array}$ & $\%$ & $\begin{array}{c}\text { Yes/tot } \\
\text { al }\end{array}$ & $\%$ \\
\hline FA & $5 / 18$ & $28 \%$ & - & $3 / 18$ & $17 \%$ & ref & $2 / 18$ & $11 \%$ & ref & $1 / 18$ & $6 \%$ & $0 / 18$ & $0 \%$ \\
\hline $\mathrm{HVO}_{\text {NOx }}$ & $\begin{array}{c}12 / 1 \\
9\end{array}$ & $63 \%$ & 0.031 & $7 / 19$ & $37 \%$ & $0.27^{\mathrm{e}}$ & $8 / 19$ & $42 \%$ & $0.062 \mathrm{e}$ & $2 / 19$ & $11 \%$ & $1 / 19$ & $5 \%$ \\
\hline $\begin{array}{c}\mathrm{HVO}_{\mathrm{PM}+\mathrm{N}} \\
\mathrm{Ox}\end{array}$ & $\begin{array}{c}14 / 1 \\
8 \\
\end{array}$ & $78 \%$ & 0.003 & $8 / 18$ & $44 \%$ & 0.07 & $9 / 18$ & $50 \%$ & 0.011 & $5 / 18$ & $28 \%$ & $3 / 18$ & $17 \%$ \\
\hline
\end{tabular}

Descriptive table of the number of volunteers reporting any type of symptoms, symptoms categorized by type, and $\chi^{2}$-tests for any reported symptoms, eye and throat symptoms. The $\chi^{2}$-tests are compared to the FA exposure. $\chi^{2}$-tests were not performed for nose and chest symptoms due to the low number of reported symptoms. The number of subjects was 19 for $\mathrm{HVO}_{\mathrm{NOx}}$ and 18 for FA and $\mathrm{HVO}_{\mathrm{PM}+\mathrm{NOx}}$. ${ }^{a}$ Itching, running and/or sore eyes. ${ }^{\mathrm{b}}$ Sore/dry/irritated throat. ${ }^{\mathrm{c}}$ Running nose and/or nose congestion. ${ }^{\mathrm{d}}$ Chest tightness/breathlessness. ${ }^{\text {e }} \mathrm{P}$ values obtained from Fisher exact test.

\section{Airway function}

Peak nasal inspiratory flow (PNIF) and peak expiratory flow (PEF)

The changes in $\triangle \mathrm{PNIF}$ and $\triangle \mathrm{PEF}$ at each time point during the exposure are shown in Fig. 4 , and absolute values are presented in Additional file E. For both PNIF and PEF, there was an increasing trend throughout the FA exposure while no such increase was seen for neither of the two HVO 
exposures. The differences between average changes in PNIF and PEF measurements $(\Delta \mathrm{PNIF}$ and $\triangle \mathrm{PEF}$ ) during the two HVO exposure scenarios compared to FA are presented in Table 4. Although no decrease in absolute PNIF values was found for the HVO exposures, we observed a statistically significant decrement in $\triangle \mathrm{PNIF}$ during $\mathrm{HVO}_{\mathrm{NO}}$ exposure compared to the FA exposure $(-18.1 \mathrm{~L}$ $\left.\min ^{-1}, \mathrm{p} \leq 0.001\right)$, and a borderline significant decrement during $\mathrm{HVO}_{\mathrm{PM}+\mathrm{NOx}}$ exposure $\left(-7.4 \mathrm{~L} \mathrm{~min}^{-1}\right.$, $\mathrm{p}=0.08)$. No difference in $\triangle \mathrm{PEF}$ was found between the HVO exposures and FA.

Table 4: The average changes in $\triangle \mathrm{PNIF}$ and $\triangle \mathrm{PEF}\left(\mathrm{L} \mathrm{min}^{-1}\right)$ during each exposure scenario and compared to the FA exposure.

\begin{tabular}{lcccccc} 
& \multicolumn{2}{c}{ PNIF } & \multicolumn{2}{c}{ PEF } \\
& $\begin{array}{l}\text { estimated mean } \\
(95 \% \mathrm{Cl})\end{array}$ & beta $(95 \% \mathrm{Cl})$ & p-value & estimated mean $(95 \% \mathrm{Cl})$ & beta $(95 \% \mathrm{Cl})$ & p-value \\
\hline \hline FA & $10.3[4.1,16.6]$ & Ref & ref & $2.2[-5.1,9.5]$ & Ref & ref \\
HVO $_{\text {NOx }}$ & $-7.7[-14.4,-1.1]$ & $-18.1[-27.3,-$ & $<0.001$ & $-2.5[-10.2,5.3]$ & $-4.6[-15.6,6.3]$ & 0.40 \\
HVO $_{P M+N O x}$ & $2.9[-3.4,9.1]$ & $-7.4[-15.6,0.8]$ & 0.08 & $4.7[-2.4,11.9]$ & $2.5[-7.1,12.2]$ & 0.60 \\
\hline
\end{tabular}

Estimated average changes in $\triangle \mathrm{PNIF}$ and $\triangle \mathrm{PEF}\left(\mathrm{L} \mathrm{min}^{-1}\right)$ during each exposure scenario (estimated mean) and differences between the two HVO exposures and FA exposure (beta). The beta values ( $\mathrm{L} \mathrm{min}^{-1}$ ) and significance ( $p$-value) are based on the linear mixed model with exposure order correction. Values within brackets are the $95 \% \mathrm{CI}$.

\section{Spirometry}

The result of the FVC (forced vital capacity), $\mathrm{FEV}_{1}$ (forced expiratory volume in one second) and $\mathrm{FEV}_{1} / \mathrm{FVC}$ (in $\mathrm{L}, \mathrm{z}$-score and as \% of predicted) is presented in Additional file F. $\mathrm{FEV}_{1}$ and FVC showed minimal and statistically insignificant differences after all exposure scenarios (Additional file F1). A minimal (from 0.81 to 0.82$)$ but statistically significant $(\mathrm{p}<0.05)$ increase in mean $\mathrm{FEV}_{1} / \mathrm{FVC}$ was found after the $\mathrm{HVO}_{\mathrm{NO}}$ exposure. Compared to FA, no significant changes were found after the HVO exposures (Additional file F2).

\section{Oscillometry parameters}


263

264

265

266

267

268

269

270

271

272

273

274

275

276

277

278

279

The results of the oscillometry parameters reflecting reactance $\left(\mathrm{X}_{5}, \mathrm{Ax}_{\mathrm{X}}, \mathrm{F}_{\mathrm{RES}}\right)$ and resistance $\left(\mathrm{R}_{5}\right.$, $\mathrm{R}_{19}$ ) are presented in Table 5. There was no statistically significant difference before and after any exposure for any parameter (median). Weak statistical evidence $(\mathrm{p}=0.084)$ was found for a decrease in reactance $\left(\mathrm{X}_{5}\right)$ after $\mathrm{HVO}_{\mathrm{NO}}$; however, similar trends were not seen for the related parameters of $A_{X}$ and $F_{\text {RES }}$ which downplays the probability of a physiological effect on the lung. Some volunteers had baseline oscillometry values deviating from the normal range $(40,41)$ but with normal spirometry measures; thus, the volunteers were further categorized into a "typical" and "atypical" group based on their oscillometric measures (Additional file A). The atypical group showed a higher proportion of having a history of symptoms and atopy (80\% vs. 54\%, p<0.05). They were hypothesized to be more sensitive and have a different lung reaction to the exposures than the typical group. However, no significant interactions between the typical/atypical groups and PNIF or PEF were found. Neither were any statistically significant changes found for any oscillometry parameters of the atypical/typical groups after the HVO exposures in comparison to FA.

Table 5 . The average lung reactance $\left(X_{5}, A_{x}\right)$, resistance $\left(R_{5}, R_{19}, R_{5-19}\right)$ and resonant frequency $\left(\mathrm{F}_{\mathrm{RES}}\right)$ before and after exposure and the paired test.

Exposure

Before exposure

After exposure

\begin{tabular}{|c|c|c|c|c|c|c|}
\hline & & median $(25 \%, 75 \%)$ & mean (Std. D) & median $(25 \%, 75 \%)$ & mean (Std. D) & $\begin{array}{c}\text { Test } \\
\text { p-values }\end{array}$ \\
\hline \multirow{3}{*}{$\begin{array}{c}\mathrm{R}_{5} \\
\left(\mathrm{cmH}_{2} \mathrm{O} \text { s L-1) }\right.\end{array}$} & $\mathrm{FA}$ & $3.56(3.28,4.16)$ & $3.66(0.87)$ & $3.86(3.17,4.31)$ & $3.82(1.07)$ & 0.215 \\
\hline & $\mathrm{HVO}_{\text {NOx }}$ & $3.75(2.86,4.74)$ & $3.98(1.33)$ & $3.87(3.13,4.86)$ & $4.17(1.67)$ & 0.494 \\
\hline & $\mathrm{HVO}_{\mathrm{PM}+\mathrm{NOx}}$ & $3.61(3.1,4.68)$ & $4.06(1.67)$ & $3.6(2.93,5.22)$ & $4.10(1.84)$ & 0.845 \\
\hline \multirow{3}{*}{$\begin{array}{c}\mathrm{R}_{19} \\
\left(\mathrm{cmH}_{2} \mathrm{O} \mathrm{s} \mathrm{L}^{-1}\right)\end{array}$} & FA & $3.09(2.63,3.77)$ & $3.11(0.73)$ & $3.24(2.67,3.71)$ & $3.20(0.71)$ & 0.286 \\
\hline & $\mathrm{HVO}_{\mathrm{NOx}}$ & $3.12(2.56,3.96)$ & $3.21(0.74)$ & $3.33(2.68,3.88)$ & $3.28(0.83)$ & 0.355 \\
\hline & $\mathrm{HVO}_{\mathrm{PM}+\mathrm{NOx}}$ & $3.14(2.61,3.82)$ & $3.17(0.86)$ & $3.03(2.54,3.97)$ & $3.26(1.00)$ & 0.215 \\
\hline \multirow{3}{*}{$\begin{array}{c}\mathrm{R}_{5-19} \\
\left(\mathrm{cmH}_{2} \mathrm{O} \mathrm{s} \mathrm{L}^{-1}\right)\end{array}$} & FA & $0.38(0.2,0.72)$ & $0.54(0.51)$ & $0.51(0.16,0.68)$ & $0.63(0.69)$ & 0.5 \\
\hline & $\mathrm{HVO}_{\mathrm{NOx}}$ & $0.79(0.18,1.11)$ & $0.77(0.80)$ & $0.72(0.24,0.98)$ & $0.88(1.08)$ & 0.212 \\
\hline & $\mathrm{HVO}_{\mathrm{PM}+\mathrm{NOx}}$ & $0.49(0.22,1.07)$ & $0.89(1.05)$ & $0.5(0.27,1.15)$ & $0.84(1.04)$ & 0.948 \\
\hline
\end{tabular}
Wilcoxon Signed Rank Test

RelatedSamples 


\begin{tabular}{ccccccc} 
& $F A$ & $-1.19(-1.34,-1.1)$ & $-1.25(0.40)$ & $-1.16(-1.38,-0.99)$ & $-1.35(0.71)$ & 0.306 \\
$\mathrm{X}_{5}$ & $\mathrm{HVO}_{\text {NOx }}$ & $-1.21(-1.45,-0.88)$ & $-1.3(0.65)$ & $-1.22(-1.53,-1.1)$ & $-1.49(1.02)$ & 0.084 \\
$\left(\mathrm{cmH}_{2} \mathrm{O} \mathrm{s} \mathrm{L}^{-1}\right)$ & $\mathrm{HVO}_{\mathrm{PM+NOx}}$ & $-1.15(-1.86,-1.07)$ & $-1.58(1.12)$ & $-1.19(-1.51,-0.99)$ & $-1.43(0.96)$ & 0.102 \\
\hline \multirow{2}{*}{$\mathrm{Ax}$} & $\mathrm{FA}$ & $5.9(4.16,8.72)$ & $7.44(5.00)$ & $5.63(2.75,8.79)$ & $7.85(6.66)$ & 0.913 \\
$\left(\mathrm{cmH}_{2} \mathrm{O} \mathrm{L}^{-1}\right)$ & $\mathrm{HVO}_{\text {NOx }}$ & $5.99(3.34,14.13)$ & $9.24(7.91)$ & $6.31(3.19,13.14)$ & $10.73(13.13)$ & 0.658 \\
& $\mathrm{HVO}_{\mathrm{PM}+\mathrm{NOx}}$ & $6.33(4.26,15.31)$ & $12.14(15.50)$ & $5.52(3.44,13.97)$ & $12.00(17.05)$ & 0.586 \\
\hline \multirow{2}{*}{$\mathrm{F}_{\mathrm{RES}}$} & $\mathrm{FA}$ & $15.38(13.59,19.47)$ & $16.28(3.88)$ & $15.64(12.9,18.88)$ & $15.93(4.41)$ & 0.528 \\
$(\mathrm{~Hz})$ & $\mathrm{HVO}_{\mathrm{NOx}}$ & $14.88(12.91,23.66)$ & $17.36(5.90)$ & $14.88(12.97,22.96)$ & $17.61(5.98)$ & 0.494 \\
& $\mathrm{HVO}_{\mathrm{PM+NOx}}$ & $16.22(12.28,22.05)$ & $17.64(5.91)$ & $14.98(13.56,19.71)$ & $17.58(7.18)$ & 0.744 \\
\hline
\end{tabular}

\section{Discussion}

We present the effects of the first controlled human chamber exposure to exhaust from renewable diesel fuel, namely, hydrotreated vegetable oil (HVO). Modern non-road vehicles with or without an aftertreatment system were used to investigate the health effects from two different but realistic exposures: 1) PM combined with $\mathrm{NO}_{\mathrm{x}}$ and, 2) $\mathrm{NO}_{\mathrm{x}}$ alone, both of which were compared to filtered air (FA) exposure. The exposure levels were designed to be close to, but below the current EU 8hour OELs for $\mathrm{NO}, \mathrm{NO}_{2}$, BTEX and PAHs (naphthalene and benzo(a)pyrene), and the future EU OEL for elemental carbon (EC, from 2023).

We found that exposures to HVO exhaust caused mild irritation symptoms compared to FA. Additionally, the observed PNIF patterns indicate that nasal obstruction occurred for both HVO exposures compared to FA. However, no overall changes in pulmonary function measured as PEF, spirometry or forced oscillation technique (FOT), were observed after 3 hours of exposure to HVO exhaust. Our findings indicate that exposure to HVO exhaust from modern non-road vehicles at relatively low exposure levels (below the future OELs) during a short period (3 hours) can cause irritative symptoms.

\section{Self-rated symptoms}

Exposure to $\mathrm{HVO}_{\mathrm{PM}+\mathrm{NOx}}$ caused a significantly higher number of reported symptoms compared to FA, and some evidence of a similar trend for symptoms of eye and throat irritation (Table 3). In 
addition to $\mathrm{PM}$ and $\mathrm{NO}_{\mathrm{x}}$, the HVOPM+NOx exposure also contained low concentrations of VOCs such as formaldehyde, BTEX and PAHs, which were not detected for $\mathrm{HVO}_{\text {NOx }}$. Formaldehyde exposure is a known irritant, causing eye and respiratory tract irritation (42), however, strong responses are generally found at much higher concentrations $\left(>200 \mu \mathrm{g} \mathrm{m}^{-3},(15,43)\right)$ than used in this study (HVOPM+NOx: $51 \pm 6 \mu \mathrm{g} \mathrm{m}^{-3}$ ). The mild symptoms of irritation in this study could hence be an effect of the formaldehyde, despite the low concentration, in combination with the other VOCs and the PM. However, the effect of $\mathrm{NO}$ or $\mathrm{NO}_{2}$ alone cannot be disregarded since there were symptoms reported for the $\mathrm{HVO}_{\mathrm{NOx}}$ exposure as well but to a lower extent. Symptoms similar to the ones observed in this study have earlier been reported by Mudway et al. (14) who found nasal, throat, and eye irritation as well as bronchoconstriction in healthy volunteers exposed to petroleum diesel at levels similar to the ones used in this study.

\section{Respiratory function}

Different patterns in PNIF values were found for the HVO and FA exposures (Fig. 4). In contrast to FA exposure, PNIF did not increase during exposure to the HVO exhaust, hence indicating a nasal obstruction during the two HVO exposures. The lack of an increase in PNIF was seen already 55 minutes into the exposure (Fig. 4). The decrements of $\triangle \mathrm{PNIF}$ were larger during the HVO $\mathrm{NOx}_{\mathrm{x}}$ exposure than during $\mathrm{HVO}_{\mathrm{PM}+\mathrm{NO}}$ in comparison to FA (Table 1). As the $\mathrm{HVO}_{\mathrm{NOx}}$ exposure did not contain any $\mathrm{PM}$ fraction $\left(\mathrm{PN}<100 \mathrm{~cm}^{-3}, \mathrm{PM} \sim 1 \mu \mathrm{g} \mathrm{m}^{-3}\right)$, the effects are attributed to the $\mathrm{NO}$ and $\mathrm{NO}_{2}$ exposure. In addition, the larger impact on the nasal patency may be related to the $\mathrm{NO}_{2}$ rather than the NO concentration since $\mathrm{NO}$ was lower during the $\mathrm{HVO}_{\mathrm{NO}}$ exposure than during HVOPM+NOx. The 3-hour average $\mathrm{NO}_{2}$ concentration was similar for the two HVO exposures but fluctuated more for $\mathrm{HVO}_{\mathrm{NOx}}$ and this caused short periods with higher concentrations (Fig. 1b). However, the impact of $\mathrm{NO}_{2}$ on nasal patency is not known, and the uptake of $\mathrm{NO}_{2}$ generally occurs deeper down in the lungs and causes effect on the small airways (44) and asthma-related respiratory effects (reviewed in [45]). In this study no overall changes in lower airway function 
(assessed with PEF, spirometry and FOT) were seen, while, for example, reduction in PEF has been reported after petroleum diesel exhaust exposures of both higher (6) and lower (9) PM and $\mathrm{NO}_{\mathrm{x}}$ exposure concentrations. However, in studies with $\mathrm{NO}_{2}$ exposures alone at similar concentrations as in this study (1-3h, 0.1-4 ppm), $\mathrm{NO}_{2}$ has not caused any significant effects on lung function (assessed by spirometry) in healthy subjects (46-49).

Another cause for the increased nasal obstruction after the two HVO exposures could potentially be due to local or pulmonary vasodilation induced by the NO exposure. NO is a known pulmonary and systemic vasodilator, and when clinically administered it causes preferential pulmonary vasodilation, which is used, for example, to treat hypoxemia and acute respiratory distress syndrome (5-80 ppm) (50,51). However, as the decrement in PNIF (compared to FA) was lower for $\mathrm{HVO}_{\mathrm{PM}+\mathrm{NO}}$, which contained higher NO than $\mathrm{HVO}_{\mathrm{NOx}}$, we cannot attribute the effect solely to NO. In addition, we cannot exclude that there is an interaction effect of the PM and gases, as the changes in nasal patency were less pronounced during $\mathrm{HVO}_{\mathrm{PM}+\mathrm{NOx}}$ than $\mathrm{HVO}_{\mathrm{NOx}}$.

The temporary changes in measured airway functions were small and unlikely to have clinical importance in healthy persons from short-term exposure. Nevertheless, we cannot exclude a risk from either short-term or long-term exposure on more sensitive persons, for example older people or those with pre-existing lung or cardiovascular disease. The long-term effect of renewable diesel exhaust is unknown, but the short-term responses in this study indicate that even exposure below the future OELs is not completely without risk for negative health effects. Reduced PNIF is not a measure of lung function, but clinically a long-term nasal obstruction caused by occupational exposure could be considered indicative for the development of irritation asthma (52).

In previous studies, oscillometry measurements found early manifestations of lung disease before these were measurable with spirometry $(53,54)$. The subjects with baseline oscillometric values 
just outside the normal range ("atypical group", Additional file A) were hence hypothesized to have a different lung reaction than persons within the normal range. Differences between the typical/atypical groups were investigated for oscillometric parameters, PNIF and PEF but due to the small sample size, no clear conclusions can be drawn. The subjects with atypical oscillometry measures showed a higher proportion of having a history of symptoms and atopy ( $80 \%$ vs. $54 \%$, $\mathrm{p}<0.05$ ) from the initial medical assessment, which indicates that they may be more sensitive to pollutants and allergens. However, studies with larger numbers of subjects need to be carried out in order to draw any conclusions. It should also be noted that this group did not show any indications of anomalies in the spirometry and for future controlled exposure studies, the oscillometry measurement may increase the possibility to investigate small differences in lung function. In addition, oscillometry may potentially be valuable in the assessment of lung function effects related to occupational exposures for early detection and disease prevention.

\section{Aerosol characteristics, deposited dose and occupational exposure limits}

The total deposited mass dose of $\mathrm{HVO}_{\mathrm{PM}+\mathrm{NOx}}$ during the 3-hours exposure $(82 \pm 32 \mu \mathrm{g}$, Fig. 3b) was comparable to the hourly mass dose for people working outdoor in relatively polluted cities during a similar time interval (50 $\mu \mathrm{g}$ PM2.5 $\left.\mathrm{h}^{-1},(55)\right)$. Compared to a previous exposure study on petroleum diesel (15), the HVO particles generated by the modern diesel engine in this study had a smaller mobility size which caused higher deposition fractions in terms of mass, surface area and number. The difference in deposition is due to the higher deposition fraction (Additional file $\mathrm{D}$ ) of smaller particles which dominated $\mathrm{HVO}_{\mathrm{PM}+\mathrm{NOx}}$ emissions (MMD 108nm) in comparison to petroleum diesel (MMD $195 \mathrm{~nm}$ ). It means that in the case of $\mathrm{HVO}_{\mathrm{PM}+\mathrm{NO}}$, two times more particles will deposit due to their smaller size in comparison to the compared petroleum diesel particles.

Modern diesel engines utilize improved combustion parameters of, for example, increased fuel injection pressure and nozzle design, which reduce the size (but not necessarily the number 
concentration) of the soot particles, which in turn reduces the soot mass emissions (36). As the upcoming OEL for the EC from diesel engines is only expressed as mass ( $50 \mu \mathrm{gC} \mathrm{m}^{-3}$, from 2023), it may be more efficient in mitigating the inhaled and deposited dose of older diesel engine emissions, but not necessarily as efficient in reducing the deposited dose from renewable fuels and modern diesel engines without DPFs. For example, even though the PM1 mass concentration (93 $\mu \mathrm{g} \mathrm{m}^{-3}$ ) was 3 times lower for HVO in this study, compared to the previous exposure study to petroleum diesel (15) with PM1 $276 \mu \mathrm{g} \mathrm{m}$-3, the average deposited mass (Table 2) was only a factor 0.8 lower (i.e., only 20\% lower). Despite the lower PM1 mass, the number concentration was similar and the surface area even higher due to the reduced particle size. OELs in terms of particle number concentration can hence be more efficient in reducing the exposure to particle emissions from renewable fuels and modern diesel engines similar to the ones used in this study. The particle size distributions and number concentrations need to be assessed in exposure studies and not only the mass in order to understand the deposition and dose dependent effects.

Even though the EU emission standards are continuously becoming more stringent with lower allowed exhaust emissions, modern non-road vehicles lacking full emission aftertreatment systems, like the two vehicles used in this study, will still be in use and pose a risk for hazardous exposure. No vehicle in this study had an external $\mathrm{NO}_{\mathrm{x}}$ reduction unit, and the implementation of one could potentially have reduced the $\mathrm{NO}_{\mathrm{x}}$ emissions and related health effects. From the results in this short-exposure study, we cannot exclude the potential risk of short- and long-term effects from exposure to renewable diesel exhaust from modern non-road vehicles that comply with the latest emission standards and the future OELs.

\section{Conclusion}

We investigated the effects on airway function after exposure to exhaust from renewable diesel fuel HVO from modern vehicles in comparison to filtered air. The vehicles were manufactured in 2019 
and complied with the current non-road engine EU emission standards. The exposure levels were kept below the EU OELs. Mild irritations symptoms (self-rated) were reported during the two HVO exposures, with a slightly higher incidence number during the exposure from the vehicle without an aftertreatment system ( $\left.\mathrm{HVO}_{\mathrm{PM}+\mathrm{NOx}}\right)$. The data also suggested that some individuals might be affected by exposure to HVO exhaust from modern work vehicles below the future EU OELs. Compared to older diesel exhaust exposures, the deposited fraction in the respiratory tract of HVO exhaust PM was higher, in terms of mass, number and surface area. The increase in deposition was due to the smaller soot particle size.

In this study, the focus was on nasal patency and pulmonary function assessments. However, to understand the full potential health effects of HVO exposures, additional analyses of the inflammatory and cardiovascular effects need to be performed. Additionally in this study, only the effects of short-term exposure to HVO exhaust were explored. This means that any conclusions about the long-term effects and effects on potentially sensitive groups need to be addressed in future studies.

Although the HVO fuel is more sustainable from a climate perspective, our study indicates that from a health perspective, the exposure levels need to be as carefully controlled as they are for petroleum diesel.

\section{Method}

\section{Study design}

In total 19 volunteers ( $9 \mathrm{f} / 10 \mathrm{~m}$, age 20-55 years) were exposed to the two types of engine emissions and particle free air during three separate 3-hour long sessions at least one week apart. The exposure scenarios discussed in this publication were: 1 ) emissions from a wheel loader without exhaust aftertreatment operated with $\left.\mathrm{HVO}\left(\mathrm{HVO}_{\mathrm{PM}+\mathrm{NOx}}\right), 2\right)$ emissions from a wheel 
loader with an aftertreatment system operated with $\mathrm{HVO}\left(\mathrm{HVO}_{\mathrm{NO}}\right)$, and 3 ) filtered air (FA). We would like to point out that the whole study also included an additional exposure scenario, namely, exposure to aerosolized dry $\mathrm{NaCl}$, the analysis and comparisons of which will be presented separately. The exposures took place in a $22 \mathrm{~m}^{3}$ stainless steel chamber with controlled relative humidity, temperature and ventilation. The study was double-blind and a maximum of four participants were exposed at the same time. All exposures took place on Tuesdays, Wednesdays and Thursdays, between 9-12 a.m., with a minimum of one week between each exposure. Before and immediately after each exposure, the participants went through medical examinations that included spirometry and used the forced oscillation technique (FOT). Self-rated symptoms, PEF (peak expiratory flow) and PNIF (peak nasal inspiratory flow) were registered four times: one time before and three times during the exposure (Table 7).

Table 7. Scheduling and time points of the reported measurements and self-rated symptoms.

\begin{tabular}{|c|c|c|c|c|c|}
\hline \multirow{2}{*}{$\begin{array}{c}\text { Item } \\
\text { Time point }\end{array}$} & \multirow{2}{*}{$\begin{array}{c}\text { Before exposure } \\
1 \\
\end{array}$} & \multicolumn{3}{|c|}{$\begin{array}{l}\text { During exposure (time after } \\
\text { exposure start in minutes) }\end{array}$} & \multirow{2}{*}{$\begin{array}{c}\text { Immediately after exposure } \\
5 \\
\end{array}$} \\
\hline & & 2 & 3 & 4 & \\
\hline Self-rated symptoms & $x$ & $35 \mathrm{~min}$ & $95 \min$ & $155 \min$ & \\
\hline $\begin{array}{l}\text { Peak Nasal Inspiratory Flow } \\
\text { (PNIF) }\end{array}$ & $\mathrm{x}$ & $55 \mathrm{~min}$ & $115 \min$ & $175 \min$ & \\
\hline Peak Expiratory Flow (PEF) & $x$ & $55 \mathrm{~min}$ & $115 \min$ & $175 \min$ & \\
\hline Spirometry & $x$ & & & & $x$ \\
\hline $\begin{array}{l}\text { Airway Oscillometry (Forced } \\
\text { Oscillation Technique, FOT) }\end{array}$ & $x$ & & & & $x$ \\
\hline
\end{tabular}

\section{Study population}

Volunteers were recruited via Lund University online channels and posters. Of the 25 volunteers who underwent the initial medical examination, 19 fulfilled the inclusion criteria and were consecutively selected for the study. The inclusion criteria were the following: men or nonpregnant women; 20-65 years old; no known lung disease; no asthma diagnosis; normal standard ECG reading; no medication that would affect the monitored parameters; non-smoker the last 
450 three years. All except one of the selected participants underwent all three exposures. One person 451 only participated in the exposure to $\mathrm{HVO}_{\mathrm{NOx}}$. Characteristics of the study group are summarized in 452 Table 8. The study was approved by the Swedish Ethical Review Authority (registration no. 2019453 03320) and performed in accordance with the Declaration of Helsinki.

Table 8. The participants' medical history and results from the initial medical examinations before commencement of the study.

\begin{tabular}{|c|c|c|}
\hline & & Subjects $(\mathrm{N}=19)$ \\
\hline & Age (median, min-max) & $29(20-55)$ \\
\hline & Female $(\mathrm{N}, \%)$ & $9(47 \%)$ \\
\hline & Previous smoker $(\mathrm{N}, \%)^{*}$ & $7(37 \%)$ \\
\hline \multirow[t]{6}{*}{ Medical history } & History of any symptoms last 12 months ( $\mathrm{N}, \%)$ & $7(37 \%)$ \\
\hline & - Eye symptoms (N, \%) & $1(5 \%)$ \\
\hline & - Nasal symptoms (N, \%) & $3(16 \%)$ \\
\hline & - Dry cough $(\mathrm{N}, \%)$ & 0 \\
\hline & History of chronic bronchitis (N, \%) & 0 \\
\hline & History of bronchial hyperreactivity $(\mathrm{N}, \%)$ & $5(26 \%)$ \\
\hline \multirow[t]{4}{*}{ History of childhood atopy } & Atopic dermatitis/Childhood eczema (N, \%) & $3(16 \%)$ \\
\hline & Allergic rhinitis/Hay fever $(\mathrm{N}, \%)$ & $1(5 \%)$ \\
\hline & Urticaria (N, \%) & $1(5 \%)$ \\
\hline & Physician-diagnosed asthma during childhood (N, \%) & $1(5 \%)$ \\
\hline Atopy & Phadiatop positive (N, \%) & $7(37 \%)$ \\
\hline \multirow{3}{*}{$\begin{array}{l}\text { Baseline spirometry (prior to } \\
\text { bronchodilation) }\end{array}$} & FVC \% pred. (median, min-max) & $92(70-106)$ \\
\hline & $\mathrm{FEV}_{1} \%$ pred. (median, min-max) & $94(73-108)$ \\
\hline & $\mathrm{FEV}_{1} / \mathrm{FVC} \%$ pred. (median, min-max) & $100(90-108)$ \\
\hline \multirow{3}{*}{$\begin{array}{l}\text { Baseline spirometry (after } \\
\text { bronchodilation) }\end{array}$} & FVC \% pred. (median, min-max) & $95(72-107)$ \\
\hline & FEV $1 \%$ pred. (median, min-max) & $97(79-109)$ \\
\hline & $\mathrm{FEV}_{1} / \mathrm{FVC} \%$ pred. (median, min-max) & $100(90-112)$ \\
\hline
\end{tabular}

All test subjects were currently non-smokers.

$\mathrm{FVC}=$ forced vital capacity, $\mathrm{FEV}_{1}=$ forced expiratory volume in one second. 


\section{Aerosol generation}

460 The exposures took place in a $22 \mathrm{~m}^{3}$ stainless steel chamber with an air exchange rate of 4 exchanges/hour. The supply air used for dilution was filtered from particles with a HEPA (highefficiency particulate absorbing) filter and from gases with an active carbon filter. The temperature was kept at $26 \pm 1^{\circ} \mathrm{C}$ and the relative humidity at $33 \pm 4 \%$.

\section{Renewable diesel exposure}

The renewable diesel exhaust exposure scenarios were generated with two types of modern offroad diesel vehicles with different net power $(\mathrm{kW})$. Both vehicles were manufactured in 2019 and complied with the current EU emission legislation. The smaller vehicle, net power $23 \mathrm{~kW}$, followed emission standard Stage IIIa (2007), and the larger vehicle with a net power of $55.4 \mathrm{~kW}$ followed Stage V (2019). The smaller vehicle was not equipped with any external exhaust aftertreatment (hereafter denoted $\mathrm{HVO}_{\mathrm{PM}+\mathrm{NO}}$ ), while the larger vehicle was equipped with a diesel oxidation catalyst (DOC) and a diesel particulate filter (DPF) (hereafter denoted HVONOx).

The vehicles were operated switching between load (lifting the fork and applying increased power) and idle with 15-minute intervals. During load, the vehicles were kept running around 1800-1900 rpm and during idle around $900 \mathrm{rpm}$. Both vehicles were run on 100\% HVO. The exhaust was extracted from the exhaust pipe of the vehicle, transported in heated tubing and diluted in two steps: first to approximately 1:20-1:30 (heated to $30^{\circ} \mathrm{C}$ ), and then to a total dilution ratio of 1:160 in the chamber. The setup was previously described by Wierzbicka et al. (15).

\section{Filtered air}

The filtered air (FA) exposure was obtained by provision of air that passed through a HEPA filter and an active carbon filter. The particle number concentration in the size range 0.02-2.5 $\mu \mathrm{m}$ was on average $71 \pm 43 \mathrm{~cm}^{-3}$, and the volatile organic compound (VOC) concentration $<10 \mathrm{ppb}$. The FA was used for comparison as a reference exposure. 


\section{Emission characterization}

\section{Online characterization}

489 The concentrations of PM2.5 mass, $\mathrm{NO}$, and $\mathrm{NO}_{2}$ were monitored online during the exposures to

490 keep levels below the pre-determined exposure limits of $150 \mu \mathrm{g} \mathrm{m}^{-3}, 1 \mathrm{ppm}$ and $2.5 \mathrm{ppm}$,

491 respectively. The online PM2.5 mass concentration was monitored by an ambient particulate monitor (TEOM series 1400a, Rupprecht \& Patashnick Co., N.Y., U.S.A.). NO and $\mathrm{NO}_{2}$ was measured with a chemiluminescence analyzer (CLD 700 AL, ECO PHYSICS AG, Switzerland). The raw gas emissions were measured with a flue gas analyzer (Testo 350, Testo AG, Germany) in order to monitor the operation of the vehicles and to ensure exposures below hazardous $\mathrm{CO}$ exposure levels (exposure averages were kept below $3 \mathrm{ppm}$ ). The $\mathrm{CO}_{2}$ concentration in the chamber was monitored with a non-dispersive infrared $\mathrm{CO}_{2}$ analyzer (LI-8020, LI-COR, Lincoln, NB, U.S.A.) and kept below 1500 ppm. The total VOC concentration (range 10-20 ooo ppb) was measured by an online photo-ionization technique (VelociCalc, model 9565-P, probe 986, TSI Inc., U.S.A.).

Particle number size distribution and number concentration

The particle number size distributions in the range 9.8-430 nm (HVO exposures) or 19-914 $\mathrm{nm}$ (FA exposures) were measured with a scanning mobility particle sizer (SMPS), including an electrostatic classifier (TSI model 3082) and condensation particle counter (CPC, model 3775, TSI). The aerodynamic size distribution of 0.5-20 $\mu \mathrm{m}$ was monitored with an aerodynamic particle sizer (APS, model 3321, TSI) during the exposures to ensure that the particle number size distributions maxima were captured with the SMPS. 
511 The particle effective density was assessed using an aerosol particle mass analyzer (APM 3600,

512 Kanomax) in combination with a differential mobility analyzer (DMA, TSI Inc., U.S.A.) and a

513 condensation particle counter (CPC, model 3075, TSI Inc., U.S.A.) (56). The effective density was

514 measured at five DMA-selected particle mobility diameters: 50, 70, 100, 150 and 300 nm. Mobility

515 size $\left(d_{p}\right)$ selection was performed with the DMA. The APM measured the mass distribution of the selected monodisperse aerosol by stepping the voltage for a constant rotating speed. The effective

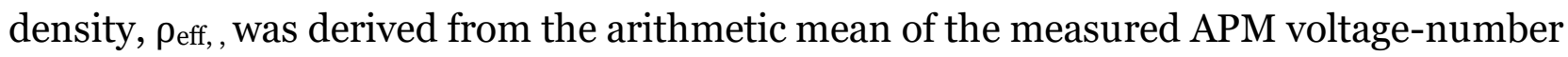
distribution and polystyrene latex spheres (PSL, Polymer Microspheres, Duke Scientific Corporation) reference data as described by McMurry et al. (56), shown in Eq. (1):

$$
\rho_{\text {eff }}=\rho_{P S L} \frac{\mathrm{v}_{A P M}}{\mathrm{v}_{A P M, P S L}}
$$

Where $\rho_{\mathrm{PSL}}$ is the density of the PSL reference particles, $\mathrm{V}_{\mathrm{APM}}$ is the measured arithmetic mean voltage of the sampled particles for a given mobility diameter and RPM, and $\mathrm{V}_{\mathrm{APM} \text {,PSL }}$ is the theoretically calculated arithmetic mean voltage of the PSL reference particles for a given mobility diameter and RPM. The DMA-APM system was calibrated with spherical PSL particles with a known density of $1.05 \mathrm{~g} \mathrm{~cm}^{-3}$.

The effective density of the $\mathrm{HVO}_{\mathrm{PM}+\mathrm{NOx}}$ (soot particles) was fitted assuming a power law function, Eq. (2) (57), where $C^{\prime \prime}$ is a constant and $D_{\text {fm }}$ the mass-mobility exponent.

$$
\rho_{e f f}=C^{\prime \prime} d_{p}^{D_{f m}-3}
$$

530 The mass-mobility relationship was used to extrapolate a power law function for the mobility equivalent particle diameters below $50 \mathrm{~nm}$ (up to the inherent material density of soot of $1.8 \mathrm{~g} \mathrm{~cm}^{-}$ 3) and above $300 \mathrm{~nm}$. 
Mass size distributions were calculated by following Eq. (3), utilizing the particle number size distribution (from the SMPS) and the experimentally determined effective density ( $\rho_{\text {eff, }}$, from the APM) as a function of electrical mobility size $\left(d_{p}\right)$.

$$
\mathrm{dM} / \operatorname{dlogd}_{\mathrm{p}}=\frac{\pi \mathrm{d}_{\mathrm{p}}^{3}}{6} * \rho_{\text {eff }}\left(\mathrm{d}_{\mathrm{p}}\right) * \mathrm{dN} / \operatorname{dlogd}_{\mathrm{p}}
$$

Lognormal distributions were fitted to the mass size distribution up to $1 \mu \mathrm{m}$ (PM1).

The surface area (SA) distributions were calculated using the model described by Rissler et al. (39), which is based on DMA-APM measurements. From the DMA-APM, the mass of individual agglomerates as a function of mobility particle size can be extracted if the effective density follows the soot power law function (Eq. 2). The surface area of individual agglomerates is then calculated by division of the mass of the agglomerate by the primary particle mass and surface area $\left(\mathrm{SA}_{\mathrm{pp}}=6 /\left(\rho_{\mathrm{pp}}{ }^{*} \mathrm{~d}_{\mathrm{pp}}\right)\right)(39)$. The primary particle size $\left(\mathrm{d}_{\mathrm{pp}}\right)$ is obtained from TEM images, and the inherent material density of soot $\left(1.8 \mathrm{~g} \mathrm{~cm}^{-3}\right)$ used for the primary particle density $\left(\rho_{\mathrm{pp}}\right)$. From the surface area of individual agglomerates as a function of mobility particle size, the particle number distribution (from the SMPS) can be converted to a particle surface area distribution. This method accounts for the agglomerated soot structure and is described in more detail by Rissler et al. and Wierzbicka et al. $(15,39)$.

\section{Offline characterization}

\section{Gravimetric analysis}

The PM1 mass concentration was determined by gravimetric analysis performed by the Division of Occupational and Environmental Medicine at Örebro University, Örebro, Sweden. The samples were collected during the entire duration of the exposure (180 minutes) using a PM1 cyclone preseparator on $37 \mathrm{~mm}$ Teflon filters (Zefluor, pore size $1.0 \mu \mathrm{m}$ ) with a flow rate of $5 \mathrm{~L} \mathrm{~min}^{-1}$. The 
filters were conditioned for 48 hours at $50 \pm 3 \% \mathrm{RH}$ and $20 \pm 1^{\circ} \mathrm{C}$ and weighed before and after collection.

\section{Thermal optical carbon analysis and TEM imaging}

Samples for the thermal optical analysis of organic carbon (OC) and elemental carbon (EC) were collected on quartz filters (47 mm, Pallflex Tissuequartz) and analyzed with a thermal optical analyzer (DRI Model 2001 OC/EC Carbon Analyzer, Atmoslytic Inc., U.S.A.) using the NIOSH NMAM 5040 diesel exhaust protocol. The limit of detection for EC (LOD) was $0.06 \mu \mathrm{g} \mathrm{C} \mathrm{cm}{ }^{-2}$. Two samples were collected in parallel, where one filter collected particle-free air after a Teflon filter (Zefluor, pore size 1.0 $\mu \mathrm{m}$ ) which was used to account for gas adsorption artifacts of the filter. Both samples were collected after a PM1 cyclone at a flow rate of $5 \mathrm{~L} \mathrm{~min}^{-1}$ during the entire exposure duration (180 $\mathrm{min})$ and stored refrigerated $\left(+6^{\circ} \mathrm{C}\right)$ until analysis.

To analyze the soot particle aggregate structure (morphology and primary particle size), samples were collected with electrostatic precipitation using a nanometer aerosol sampler (model 3089, TSI) on lacey carbon coated $\mathrm{Cu}$-grids and analyzed with a transmission electron microscope (TEM, JEOL $3000 F)$. The TEM was operated at $300 k \mathrm{k}$ and equipped with a Schottky FEG and 2x2k CCD. An overview of the samples was first imaged at $10,000 \mathrm{X}$ magnification in order to ensure that the sample was reasonably homogenous. The TEM images of $\mathrm{HVO}_{\mathrm{PM}+\mathrm{NOx}}$ were analyzed for primary particle size determination with the ImageJ software (58). The diameters of the clear primary particles without overlap at the edges of the soot agglomerates were measured in TEM images with a magnification minimum of 25,000X. The diameters of 81 primary particles were measured from 10 agglomerates.

\section{PAH analysis}

Samples for particulate PAH analysis were collected at a flow rate of $2 \mathrm{~L} \mathrm{~min}{ }^{-1}$ during the entire exposure duration (180 minutes) on Teflon filters (diameter $37 \mathrm{~mm}$, pore size $2 \mu \mathrm{m}$ (Teflo, Pall 
Corporation, Port Washington, N.Y., U.S.A.). These filters were followed by XAD-2 tubes (SKC Inc.) for sampling of gaseous PAHs. The samples were stored at $-18^{\circ} \mathrm{C}$ prior to analysis. The samples were analyzed for 33 native and alkylated PAHs (including the 16 U.S. EPA priority PAHs), 17 nitrated, 10 oxygenated PAHs (nitro-PAHs and oxy-PAHs), and 6 dibenzothiophenes (DBTs), as described by Gren et al. 2020 (22). In short, prior to extraction two labelled internal standard mixtures containing 16 deuterated U.S. EPA priority PAHs were spiked to the filters and XAD-2 adsorbent, respectively. Samples were extracted with $3 \mathrm{~mL}$ dichloromethane, cleaned using silica columns and concentrated to a final volume of approximately 30-40 $\mu \mathrm{L}$. Target compounds were separated on an Agilent 5975C mass spectrometer (MS) coupled to a $7890 \mathrm{~A}$ gas chromatograph (GC, Agilent Technologies, Santa Clara, CA, U.S.A.). The MS was operated in selected ion monitoring mode (SIM), and electron impact ionization (EI) was performed for PAHs and alkylated PAHs.

\section{Formaldehyde and BTEX analysis}

Accredited formaldehyde analysis was performed by the Division of Occupational and Environmental Medicine at Örebro University, Örebro, Sweden. The samples for formaldehyde analysis were collected with a flow rate of $0.2 \mathrm{~L} \mathrm{~min}^{-1}$ during the entire duration of the exposures (180 min) on Sep-Pak DNPH-silica cartridges (Waters). 2,4-dinitrophenylhydrazine (DNPH) formed derivates with aldehydes and were extracted in acetonitrile. The extracted samples were analyzed with liquid chromatography ultraviolet mass spectrometry (LC-UV/MS) at wavelength $360 \mathrm{~nm}$. The samples were stored at $-18^{\circ} \mathrm{C}$ prior to analysis.

An accredited analysis of benzene, toluene, ethyl benzene, $\mathrm{m}+\mathrm{p}$ xylene and o-xylene (BTEX) was performed by the IVL Swedish Environmental Research Institute, Gothenburg, Sweden. n-butyl acetate, n-octane and n-nonane were also analyzed but not included in the total BTEX concentration. The samples were collected on thermal desorption tubes (TENAX TA) and analyzed 
by a thermal desorption GC-MS method. The sorbent tubes were heated to $250^{\circ} \mathrm{C}$ under a helium

613 flow for 5 minutes. The emitted compounds were refocused with a cold trap $\left(-30^{\circ} \mathrm{C}\right)$ and then

614 quickly heated to $300^{\circ} \mathrm{C}$ in the thermal desorption instrument (Unity2 and Ultra, Markes) and

615 injected into the GC-MS (ThermoFisher Scientific). Target compounds were separated on a non-

616 polar capillary column (TraceGold, TG-1MS, ThermoFisher Scientific) coupled to a mass spectrometer (ISQ LT, ThermoFisher Scientific).

\section{Model for particle deposition in the respiratory tract}

620 Regional respiratory tract particle deposition fractions from nasal breathing were calculated for

621 the inhaled aerosols with the multiple-path particle dosimetry model (MPPD model version 3.04, 622 (59)). The input parameters are summarized in Table 9.

Table 9. The input parameters for the MPPD model used for estimating the respiratory tract particle deposition.

\begin{tabular}{|c|c|c|c|}
\hline \multicolumn{2}{|c|}{ MPPD model input data } & \multirow{2}{*}{$\begin{array}{c}\text { HVOPM+NOx } \\
\text { Yeh/Schum Symmetric }\end{array}$} & \multirow[t]{2}{*}{ Diesel (Wierzbicka et al. [2014]) } \\
\hline & Model & & \\
\hline & $\begin{array}{l}\text { Functional residual capacitya }(\mathrm{mL}) \\
\text { (median, min-max) }\end{array}$ & $3200(2680-3750)$ & \\
\hline & Upper respiratory tract volume $(\mathrm{mL})$ & 50 & \\
\hline \multirow[t]{4}{*}{ Particle properties* } & Density at $\mathrm{MMD}\left(\mathrm{g} \mathrm{cm}^{-3}\right)$ & 0.84 & 0.42 \\
\hline & $\begin{array}{l}\text { PM1 mass }\left(\mu \mathrm{g} \mathrm{m}^{-3}\right) \\
\text { (average } \pm 1 \text { std. dev.) }\end{array}$ & $93 \pm 13$ & $276 \pm 56$ \\
\hline & Mass Median Diameter (MMD) $(\mu \mathrm{m})$ & 0.108 & 0.195 \\
\hline & GSD & 1.48 & 1.65 \\
\hline \multirow[t]{7}{*}{ Exposure scenario } & Inhalability adjustment & No & \\
\hline & Acceleration of gravity $\left(\mathrm{m} \mathrm{s}^{-2}\right)$ & 9.81 & \\
\hline & Body orientation & Upright & \\
\hline & $\begin{array}{l}\text { Breathing frequency } \mathrm{b}\left(\mathrm{min}^{-1}\right) \\
\text { (median, min-max) }\end{array}$ & $17.1(13.3-24.9)$ & \\
\hline & $\begin{array}{l}\text { Tidal volume }{ }^{\mathrm{c}(\mathrm{mL})} \\
\text { (median, min-max) }\end{array}$ & $875(440-1500)$ & \\
\hline & Inspiratory fraction & 0.5 & \\
\hline & Breathing scenario & Nasal & \\
\hline
\end{tabular}

The aerosol characteristics from a previous diesel exposure study (15) were included and used in the MPPD model to compare the respiratory deposition of HVO and petroleum diesel. The MPPD model's reference values from ICRP (6o) for upper respiratory tract volume and inspiratory fraction were used. * Properties from the exposure aerosol characterization. ${ }^{a}$ Calculated by height, age and sex following the guidelines of the European Respiratory Society (61). ${ }^{\mathrm{b}}$ Measured with a Noxturnal 5.1 breathing belt (Nox 
Medical, ResMed). ${ }^{\mathrm{c}}$ Measured by a forced oscillometry technique with the Tremoflo (THORASYS, Thoracic Medical System Inc., Montreal, Canada).

The inhaled and deposited dose from oral breathing during the $\mathrm{HVO}_{\mathrm{PM}+\mathrm{NOx}}$ exposure was also calculated. This was done with the experimental model reported by Rissler et al. (39) to allow for comparison with a previous exposure study of petroleum diesel exhaust, where this model was used, and was performed with the same exposure setup (15).

\section{Medical assessment}

Nasal patency and pulmonary function measures

634 Assessment of nasal patency was performed with measurements of peak nasal inspiratory flow (PNIF) using an inspiratory flow meter (In-check, Clement Clarke International Ltd., U.K.) according to the manufacturer's instructions. Three recordings at each time point (Table 7) were performed and the highest value was used for analysis (62). The PNIF measurements were compared to the baseline value before the exposure on an individual basis, and a decrease in PNIF indicated an increased nasal obstruction (63).

Lower airway function was assessed with measurements of peak expiratory flow (PEF) measured with a MINI Wright Flow Meter (Clement Clarke International Ltd., U.K.), measuring range of 60$800 \mathrm{~L} / \mathrm{min}$. Three recordings at each time point (Table 7) were performed and the highest value was used for analysis (64). The PEF measurements were compared to the baseline value before the exposure on an individual basis, and a decrease in PEF was used as an indication of lower airway obstruction.

Spirometry was performed with SPIRARE 3 (DIAGNOSTICA, Oslo, Norway) according to the 
in the first second $\left(\mathrm{FEV}_{1}\right), \mathrm{FEV} 1 / \mathrm{FVC}$, and z-scores were obtained and compared according to the reference of the Global Lung Initiative (65).

Measures of oscillometry (resistance [R], reactance [X]) were obtained in a frequency range of 5-19 Hz by the forced oscillometric technique (FOT), with a Tremoflo (THORASYS, Thoracic Medical System Inc., Canada) according to the manufacturer's instructions (40). The resistance at 5 and 19 $\mathrm{Hz}\left(\mathrm{R}_{5}, \mathrm{R}_{19}\right)$, reactance at $5 \mathrm{~Hz}$, area under the reactance curve from 5 to $19 \mathrm{~Hz}\left(\mathrm{Ax}_{\mathrm{x}}\right)$, and the resonant frequency $\left(\mathrm{F}_{\text {res }}\right)$ before all exposures were averaged and summarized for all volunteers in Additional file A. The individual oscillograms were evaluated by a trained physician. Some volunteers had FOT values deviating from the normal range $(40,41)$ but with normal spirometry measures, thus the volunteers were further categorized into a "typical" and "atypical" group based on their oscillometric measurements. The criteria were as follows: $\mathrm{R}_{5-19} \geq 0.8 \mathrm{cmH}_{2} \mathrm{O} \mathrm{s} \mathrm{L}^{-1}, \mathrm{X}_{5} \leq-$ $1.8 \mathrm{cmH}_{2} \mathrm{O} \mathrm{s} \mathrm{L}^{-1}$, and $\mathrm{A}_{\mathrm{x}} \geq 14 \mathrm{cmH}_{2} \mathrm{O} \mathrm{L}^{-1}$ (Additional file A). These criteria were based on characteristics of healthy and asthmatic subjects as published by Eddy et al. (41). The atypical group showed a higher proportion of having a history of symptoms and atopy (80\% vs. 54\%, $\mathrm{p}<0.05)$. They were hypothesized to be more sensitive and to have a different lung reaction than the typical group, which was explored further in the analyses.

\section{Self-rated symptoms}

Similar to a previous study (6), self-rated symptoms of eye irritation, nose irritation (including runny nose and nasal congestion), throat irritation and chest tightness/breathlessness were rated by the volunteers themselves on a visual analog scale (VAS) (range o to 100 millimeter) before exposure, and at 35, 95 and $155 \mathrm{~min}$ into the exposure during each exposure session (Table 7).

\section{Statistical analysis}


For each self-rated symptom (eye, nose, throat, and chest), when a volunteer gave a higher score than before the exposure at any time during the exposure, this person was recoded as "reported symptoms", otherwise, "no reported symptoms". A person was then recoded as "reported any symptom" if he/she reported any of the four symptoms during the exposure. The calculation was performed for each exposure scenario separately. Descriptive analysis was used to count the number of persons and corresponding proportion of persons with reported symptoms during exposure for each exposure scenario. An $\chi^{2}$-test was used to investigate the difference in proportion between the given exposure scenarios (each of the two exposure scenarios) in comparison to FA exposure when applicable.

For PNIF and PEF measurements that were performed three times during each exposure, absolute changes from before exposure were calculated on the individual level for each exposure scenario at each time point. Linear mixed models were used to analyze the average changes in the selected outcomes at given exposure scenarios versus changes at FA exposure. Subject ID, the exposure scenarios and time points (1-4) were used to identify repeated measurements, and all models included a random slope. The models further included exposure order (e.g., first or second time in the chamber) as an adjustment since the order was imbalanced and a learning effect on the measurement performance might have occurred.

For spirometry and FOT measurements, which were only performed before and after exposure, the Wilcoxon signed-rank test was used to compare the differences between before and after exposure at each exposure scenario.

Additionally, interaction terms between exposure scenarios and typical/atypical groups were tested for PNIF, PEF and with the FOT in the linear mixed models described above, to see if the atypical group with FOT measurements outside the normal range (Additional file A) showed different exposure-related changes in nasal patency and pulmonary function. If the interaction 
701 terms had a p-value $<0.05$, further stratified analyses were performed in each group for selected outcomes.

All statistical analyses were performed using IBM SPSS Statistics 26. For all tests, p-values $<0.1$ were considered as weak indications, while $\mathrm{P}$ values $<0.05$ were generally accepted as significant.

\section{Declarations}

\section{Acknowledgements}

The authors thank Anders Olsson for practical help with vehicle maintenance. Panu Karjalainen is acknowledged for support with initial vehicle tests. Yuliya Omelekhina is acknowledged for practical help with aerosol sample collection. Madeleine Petersson and Veronica Ideböhn are acknowledged for contributions to composing the ethical application.

\section{Authors' contributions}

Original project idea and obtaining funding: AG and AW. Exposure scenarios design: AW and LG. Project management and coordination of exposures: AW. Aerosol generation: LG, JP, AW, AG. Initial test and selection of vehicles: LG, JP. Aerosol instrument data collection: LG, FM. Aerosol instrument data analysis and lung deposition analysis: LG. TEM images and analysis: LG. Carried out the experiments: LG, KD, EA, JN, FM. Vehicle operation: FM. PAH analysis: AMK, BS. OCEC analysis: KL. Medical assessment and measurements: KD, EA, JN. FOT data analysis and interpretation: LG, KD, PW. Statistical analysis: YX. Health effects/medical data interpretation: LG, KD, MK, MA, JN, AW, AG, JL. LG wrote the manuscript and conceived the figures. All coauthors contributed to critical revisions of the manuscript. All co-authors will have approved the final manuscript. 


\section{Funding}

728 This research was financed by the Swedish Research Council FORMAS (2016-00824). Jakob

729 Löndahl acknowledges funding from the Swedish Research Council for Health, Working Live and

730 Welfare FORTE (project number 2017-00690).

\section{Availability of data and materials}

The datasets used and/or analyzed during the current study are available from the corresponding author on reasonable request.

\section{Ethics approval and consent to participate}

The study was approved by the Swedish Ethical Review Authority (registration no. 2019-03320) and performed in accordance with the Declaration of Helsinki and included obtaining informed written consent.

\section{Consent for publication}

742 Not applicable

\section{Competing interests}

745 The authors declare that they have no competing interests.

\section{Abbreviations}

APM aerosol particle mass analyzer

749 BTEX benzene, toluene, ethyl benzene, $\mathrm{m}+\mathrm{p}$ xylene, $\mathrm{o}$-xylene

750 CI confidence interval

751 DMA differential mobility analyzer

752 DPF diesel particle filter 
753 DOC diesel oxidation catalyst

754 EC elemental carbon

755 FA filtered air

756 FEV forced expiratory volume

757 FOT forced oscillation technique

$758 \quad$ FVC forced vital capacity

759 HVO hydrotreated vegetable oil

760 MMD mass median diameter

761 MPPD multiple-path particle dosimetry model

762 NO nitrogen monoxide

$763 \quad \mathrm{NO}_{2} \quad$ nitrogen dioxide

$764 \mathrm{NO}_{\mathrm{x}} \quad$ nitrogen oxides

765 OELs occupational exposure limits

766 PAHs polycyclic aromatic hydrocarbons

767 PEF peak expiratory flow

768 PM particulate matter

$769 \quad$ PN particle number

770 PNIF peak nasal inspiratory flow

771 SA surface area

772 TEM transmission electron microscope

773 VAS visual analog scale

$774 \quad$ VOC $\quad$ volatile organic compound

777 1. Hesterberg TW, Long CM, Lapin CA, Hamade AK, Valberg PA. Diesel exhaust particulate (DEP) and nanoparticle exposures: What do DEP human clinical studies tell us about 
potential human health hazards of nanoparticles. Inhal Toxicol. 2010;22(8):679-94.

2. Ris C. U.S. EPA Health assessment for diesel engine exhaust: A review. Inhal Toxicol. 2007;19(SUPPL. 1):229-39.

3. Riedl M, Diaz-Sanchez D. Biology of diesel exhaust effects on respiratory function. J Allergy Clin Immunol. 2005;115(2):221-8.

4. Sydbom A, Blomberg A, Parnia S, Stenfors N, Sandström T, Dahlén S-E. Health effects of diesel exhaust. Clin Occup Environ Med. 2003;3(1):61-80.

5. IARC. Diesel and Gasoline Engine Exhausts and Some Nitroarenes. Vol. 105, IARC monographs on the evaluation of carcinogenic risks to humans. 2014.

6. Xu Y, Barregard L, Nielsen J, Gudmundsson A, Wierzbicka A, Axmon A, et al. Effects of diesel exposure on lung function and inflammation biomarkers from airway and peripheral blood of healthy volunteers in a chamber study. Part Fibre Toxicol. 2013;10(1):1-9.

7. Rudell B, Ledin MC, Hammarström U, Stjernberg N, Lundbäck B, Sandström T. Effects on symptoms and lung function in humans experimentally exposed to diesel exhaust. Occup Environ Med. 1996;53(10):658-62.

8. Mehus AA, Reed RJ, Lee VST, Littau SR, Hu C, Lutz EA, et al. Comparison of acute health effects from exposures to diesel and biodiesel fuel emissions. J Occup Environ Med. 2015;57(7):705-12.

9. Andersen MHG, Frederiksen M, Saber AT, Wils RS, Fonseca AS, Koponen IK, et al. Health effects of exposure to diesel exhaust in diesel-powered trains. Part Fibre Toxicol. 2019;16(1):1-14.

10. Stenfors N, Nordenhäll C, Salvi SS, Mudway I, Söderberg M, Blomberg A, et al. Different airway inflammatory responses in asthmatic and healthy humans exposed to diesel. Eur Respir J. 2004;23(1):82-6.

11. Salvi S, Blomberg A, Rudell B, Kelly F, Sandström T, Holgate ST, et al. Acute inflammatory responses in the airways and peripheral blood after short-term exposure to diesel exhaust in 
healthy human volunteers. Am J Respir Crit Care Med. 1999;159(3):702-9.

12. Salvi SS, Nordenhall C, Blomberg A, Rudell B, Pourazar J, Kelly FJ, et al. Acute exposure to diesel exhaust increases IL-8 and GRO- $\alpha$ production in healthy human airways. Am J Respir Crit Care Med. 2000;161(2 I):550-7.

13. Behndig AF, Mudway IS, Brown JL, Stenfors N, Helleday R, Duggan ST, et al. Airway antioxidant and inflammatory responses to diesel exhaust exposure in healthy humans. Eur Respir J. 2006;27(2):359-65.

14. Mudway IS, Stenfors N, Duggan ST, Roxborough H, Zielinski H, Marklund SL, et al. An in vitro and in vivo investigation of the effects of diesel exhaust on human airway lining fluid antioxidants. Arch Biochem Biophys. 2004;423(1):200-12.

15. Wierzbicka A, Nilsson PT, Rissler J, Sallsten G, Xu Y, Pagels JH, et al. Detailed diesel exhaust characteristics including particle surface area and lung deposited dose for better understanding of health effects in human chamber exposure studies. Atmos Environ. 2014;86:212-9.

16. Lundbäck M, Mills NL, Lucking A, Barath S, Donaldson K, Newby DE, et al. Experimental exposure to diesel exhaust increases arterial stiffness in man. Part Fibre Toxicol. 2009;6:16.

17. Mills NL, Törnqvist H, Gonzalez MC, Vink E, Robinson SD, Söderberg S, et al. Ischemic and thrombotic effects of dilute diesel-exhaust inhalation in men with coronary heart disease. $\mathrm{N}$ Engl J Med. 2007;357(11):1075-82.

18. Langrish JP, Bosson J, Unosson J, Muala A, Newby DE, Mills NL, et al. Cardiovascular effects of particulate air pollution exposure: Time course and underlying mechanisms. J Intern Med. 2012;272(3):224-39.

19. Lapuerta M, Armas O, Rodríguez-Fernández J. Effect of biodiesel fuels on diesel engine emissions. Prog Energy Combust Sci. 2008;34(2):198-223.

20. Murtonen T, Aakko-Saksa P, Kuronen M, Mikkonen S, Lehtoranta K. Emissions with heavy- 
duty diesel engines and vehicles using FAME, HVO and GTL fuels with and without DOC+ POC aftertreatment. SAE Int J Fuels Lubr. 2010;2(2):147-66.

21. Kuronen M, Mikkonen S, Aakko P, Murtonen T. Hydrotreated Vegetable Oil as Fuel for Heavy Duty Diesel Engines. 2007;(724). Available from: http://www.sae.org/technical/papers/2007-01-4031

22. Gren L, Malmborg VB, Jacobsen NR, Shukla PC, Bendtsen KM, Eriksson AC, et al. Effect of renewable fuels and intake $\mathrm{O} 2$ concentration on diesel engine emission characteristics and reactive oxygen species (ROS) formation. Atmosphere (Basel). 2020;11(6).

23. Unosson J, Kabele M, Boman C, Nyström R, Sadiktsis I, Westerholm R, et al. Acute cardiovascular effects of controlled exposure to dilute petrodiesel and biodiesel exhaust in healthy volunteers: A crossover study. Res Sq. 2020;1-29.

24. Matti Maricq M. Chemical characterization of particulate emissions from diesel engines: A review. J Aerosol Sci. 2007;38(11):1079-118.

25. Savic N, Rahman MM, Miljevic B, Saathoff H, Naumann KH, Leisner T, et al. Influence of biodiesel fuel composition on the morphology and microstructure of particles emitted from diesel engines. Carbon N Y. 2016;

26. Knothe G, Krahl J, Van Gerpen J. The biodiesel handbook. Elsevier; 2015.

27. Rodríguez-Fernández J, Lapuerta M, Sánchez-Valdepeñas J. Regeneration of diesel particulate filters: Effect of renewable fuels. Renew Energy. 2017;104:30-9.

28. Gren L, Malmborg VB, Falk J, Markula L, Novakovic M, Shamun S, et al. Effects of renewable fuel and exhaust aftertreatment on primary and secondary emissions from a modern heavy-duty diesel engine. J Aerosol Sci. 2021;156(November 2020):105781.

29. European Council. Directive (EU) 2019/130 of the European Parliament and of the Council of 16 January 2019 amending Directive 2004/37/EC on the protection of workers from the risks related to exposure to carcinogens or mutagens at work (Text with EEA relevance.). Vol. 30. 2019. 
30. European Council. Directive (2004/37/EC) of the European Parliament and of the Council amending the Protection of Workers from the Risks Related to Exposure to Carcinogenic or Mutagens at Work. Off J Eur Union. 2017;

31. Liu ZG, Eckerle WA, Ottinger NA. Gas-phase and semivolatile organic emissions from a modern nonroad diesel engine equipped with advanced aftertreatment. J Air Waste Manag Assoc. 2018;68(12):1333-45.

32. Zeraati-Rezaei S, Alam MS, Xu H, Beddows DC, Harrison RM. Size-resolved physicochemical characterization of diesel exhaust particles and efficiency of exhaust aftertreatment. Atmos Environ. 2020;222(October 2019):117021.

33. Reşitoĝlu IA, Altinişik K, Keskin A. The pollutant emissions from diesel-engine vehicles and exhaust aftertreatment systems. Clean Technol Environ Policy. 2015;17(1):15-27.

34. Landwehr KR, Larcombe AN, Reid A, Mullins BJ. Critical Review of Diesel Exhaust Exposure Health Impact Research Relevant to Occupational Settings: Are We Controlling the Wrong Pollutants? Exposure and Health. Springer Netherlands; 2020.

35. Knecht W. Diesel engine development in view of reduced emission standards. Energy. 2008;33(2):264-71.

36. Hielscher K, Brauer M, Baar R. Reduction of soot emissions in diesel engines due to increased air utilization by new spray hole configurations. Automot Engine Technol. 2016;1(1-4):69-79.

37. Finlay WH, Martin AR. Recent advances in predictive understanding of respiratory tract deposition. J Aerosol Med Pulm Drug Deliv. 2008;21(2):189-206.

38. Park K, Kittelson DB, McMurry PH. Structural properties of diesel exhaust particles measured by Transmission Electron Microscopy (TEM): Relationships to particle mass and mobility. Aerosol Sci Technol. 2004;38(9):881-9.

39. Rissler J, Swietlicki E, Bengtsson A, Boman C, Pagels J, Sandström T, et al. Experimental determination of deposition of diesel exhaust particles in the human respiratory tract. $J$ 
Aerosol Sci. 2012;48:18-33.

40. Lundblad LKA, Siddiqui S, Bossé Y, Dandurand RJ. Applications of oscillometry in clinical research and practice. Can J Respir Crit Care, Sleep Med. 2019;0(o):1-15.

41. Eddy RL, Westcott A, Maksym GN, Parraga G, Dandurand RJ. Oscillometry and pulmonary magnetic resonance imaging in asthma and COPD. Physiol Rep. 2019;7(1):1-12.

42. Arts JHE, Rennen MAJ, De Heer C. Inhaled formaldehyde: Evaluation of sensory irritation in relation to carcinogenicity. Regul Toxicol Pharmacol. 2006;44(2):144-60.

43. Lang I, Bruckner T, Triebig G. Formaldehyde and chemosensory irritation in humans: A controlled human exposure study. Regul Toxicol Pharmacol. 20o8;50(1):23-36.

44. Sandstrom T. Respiratory effects of air pollutants: Experimental studies in humans. Eur Respir J. 1995;8(6):976-95.

45. EPA. Integrated Science Assessment for Oxides of Nitrogen - Health Criteria. 2016.

46. Frampton MW, Boscia J, Roberts NJ, Azadniv M, Torres A, Christopher COX, et al. Nitrogen dioxide exposure: Effects on airway and blood cells. Am J Physiol - Lung Cell Mol Physiol. 2002;282(1 26-1):155-65.

47. Frampton MW, Morrow PE, Cox C, Gibb FR, Speers DM UM. Effects of nitrogen dioxide exposure on pulmonary function and airway reactivity in normal humans. Am Rev Respir Dis. 1991; Mar 143(3):522-7.

48. Brand P, Bertram J, Chaker A, Jörres RA, Kronseder A, Kraus T, et al. Biological effects of inhaled nitrogen dioxide in healthy human subjects. Int Arch Occup Environ Health. 2016;89(6):1017-24.

49. Langrish JP, Lundbäck M, Barath S, Söderberg S, Mills NL, Newby DE, et al. Exposure to nitrogen dioxide is not associated with vascular dysfunction in man. Inhal Toxicol. 2010;22(3):192-8.

50. Creagh-Brown BC, Griffiths MJD, Evans TW. Bench-to-bedside review: Inhaled nitric oxide therapy in adults. Crit Care. 2009;13(3):221. 
51. Yu B, Ichinose F, Bloch DB, Zapol WM. Inhaled nitric oxide. Br J Pharmacol. 2019;176(2):246-55.

52. Shusterman D. Occupational irritant and allergic rhinitis. Curr Allergy Asthma Rep. 2014;14(4).

53. Zaidan MF, Reddy AP, Duarte A. Impedance oscillometry: Emerging role in the management of chronic respiratory disease. Curr Allergy Asthma Rep. 2018;18(1).

54. Frantz S, Nihlén U, Dencker M, Engström G, Löfdahl CG, Wollmer P. Impulse oscillometry may be of value in detecting early manifestations of COPD. Respir Med. 2012;106(8):111623.

55. Hussein T, Saleh SSA, dos Santos VN, Boor BE, Koivisto AJ, Löndahl J. Regional inhaled deposited dose of urban aerosols in an eastern Mediterranean city. Atmosphere (Basel). 2019;10(9).

56. McMurry PH, Wang X, Park K, Ehara K. The relationship between mass and mobility for atmospheric particles: A new technique for measuring particle density. Aerosol Sci Technol. 2002;36(2):227-38.

57. Park K, Cao F, Kittelson DB, McMurry PH. Relationship between particle mass and mobility for diesel exhaust particles. Environ Sci Technol. 2003;37(3):577-83.

58. Schneider CA, Rasband WS, Eliceiri KW. NIH Image to ImageJ: 25 years of image analysis. Nat Methods. 2012;9(7):671-5.

59. Asgharian B, Hofmann W, Bergmann R. Particle deposition in a multiple-path model of the human lung. Aerosol Sci Technol. 2001;34(4):332-9.

60. ICRP. Human Respiratory Tract Model for Radiological Protection. Ann ICRP 24. 1994;ICRP Publi:(1-3).

61. Stocks J, Quanjer PH. Reference values for residual volume, functional residual capacity and total lung capacity: ATS Workshop on Lung Volume Measurements Official Statement of the European Respiratory Society. Eur Respir J. 1995;8(3):492-506. 
935 62. Ottaviano G, Scadding GK, Coles S, Lund VJ. Peak nasal inspiratory flow; normal range in adult population. Rhinology. 2006;44(1):32-5.

937 63. Mo S, Gupta SS, Stroud A, Strazdins E, Hamizan AW, Rimmer J, et al. Nasal Peak Inspiratory Flow in Healthy and Obstructed Patients: Systematic Review and Meta-Analysis. Laryngoscope. 2021;131(2):260-7.

64. Graham BL, Steenbruggen I, Barjaktarevic IZ, Cooper BG, Hall GL, Hallstrand TS, et al. Standardization of spirometry 2019 update an official American Thoracic Society and European Respiratory Society technical statement. Am J Respir Crit Care Med. 2019;200(8):E70-88.

65. Quanjer PH, Stanojevic S, Cole TJ, Baur X, Hall GL, Culver BH, et al. Multi-ethnic reference values for spirometry for the 3-95-yr age range: The global lung function 2012 equations. Eur Respir J. 2012;40(6):1324-43. 
Figures
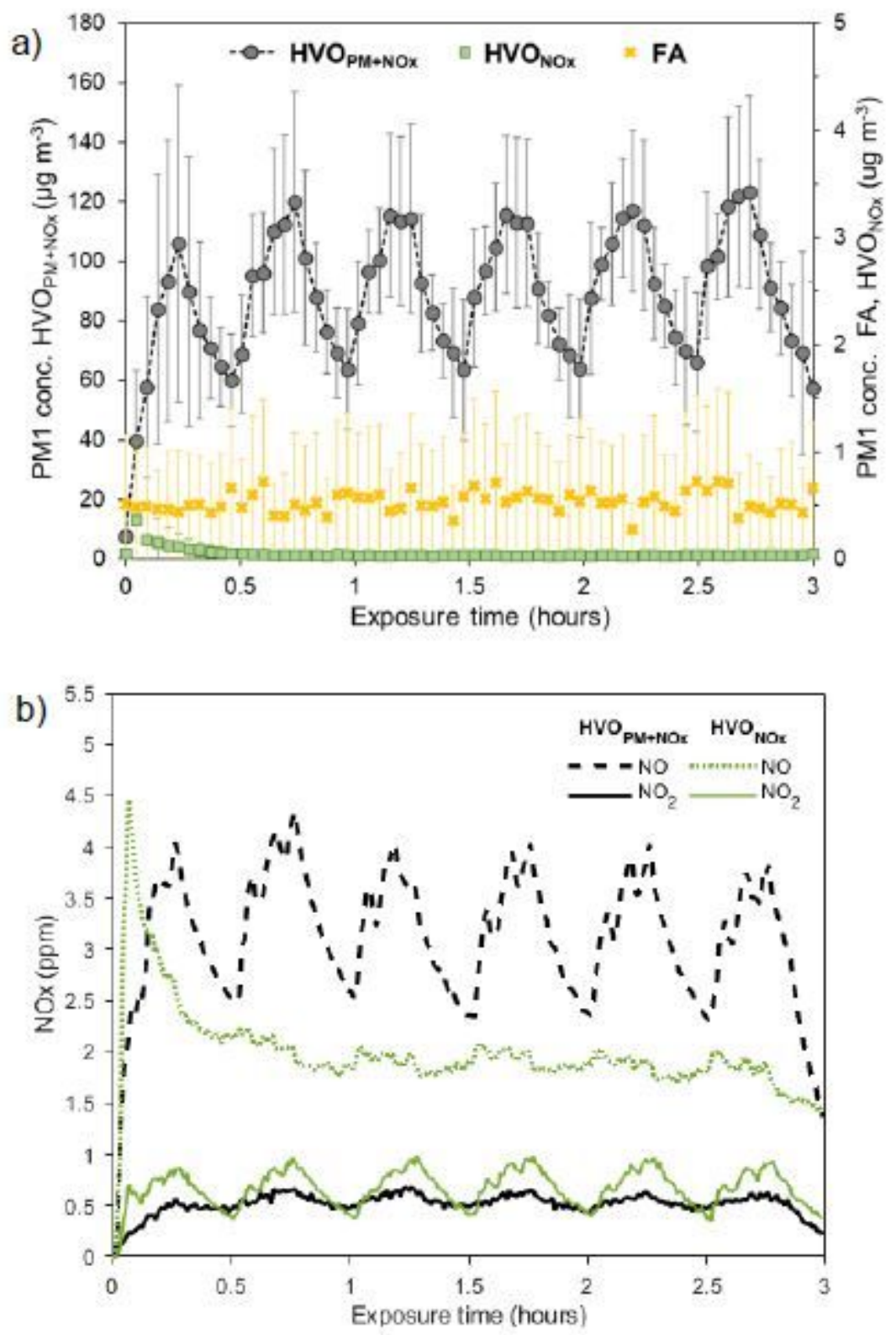

Figure 1

please see the manuscript file for the full caption 


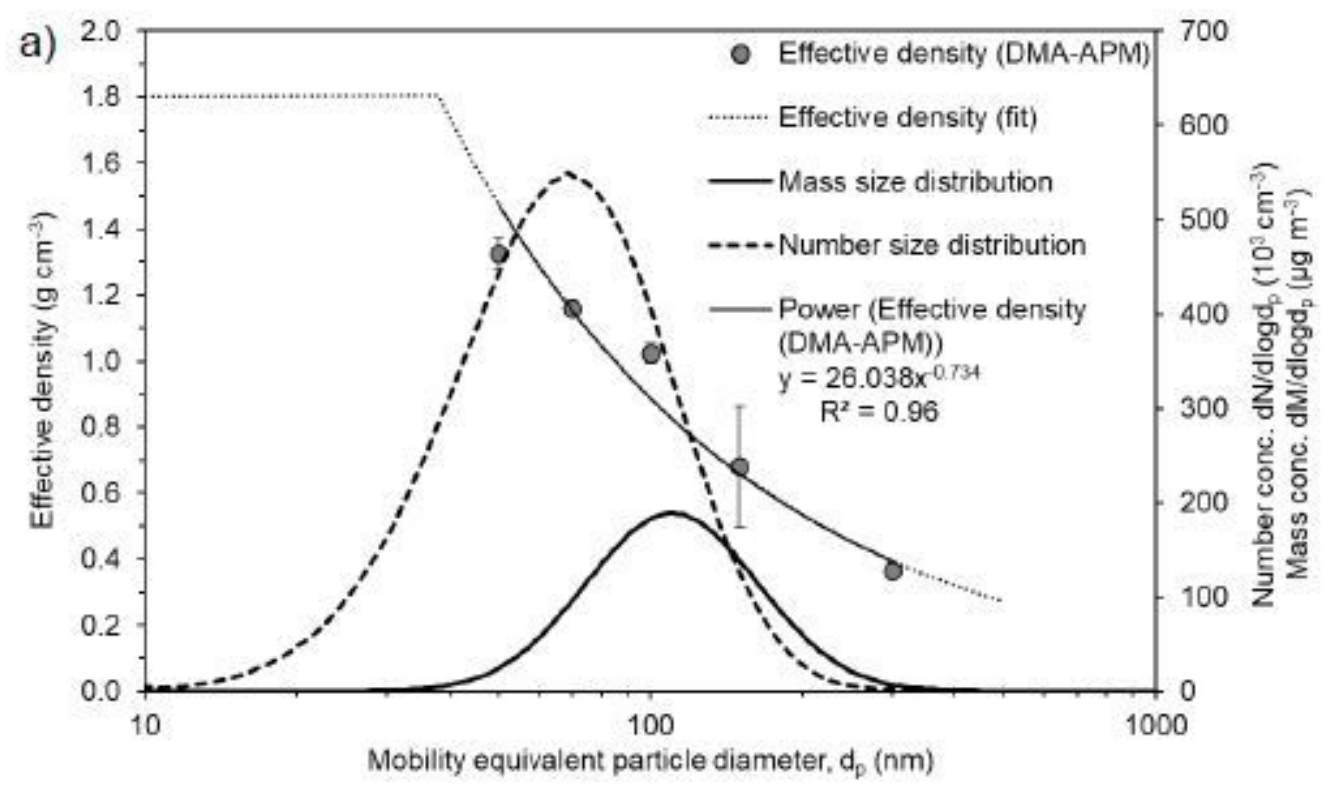

b)

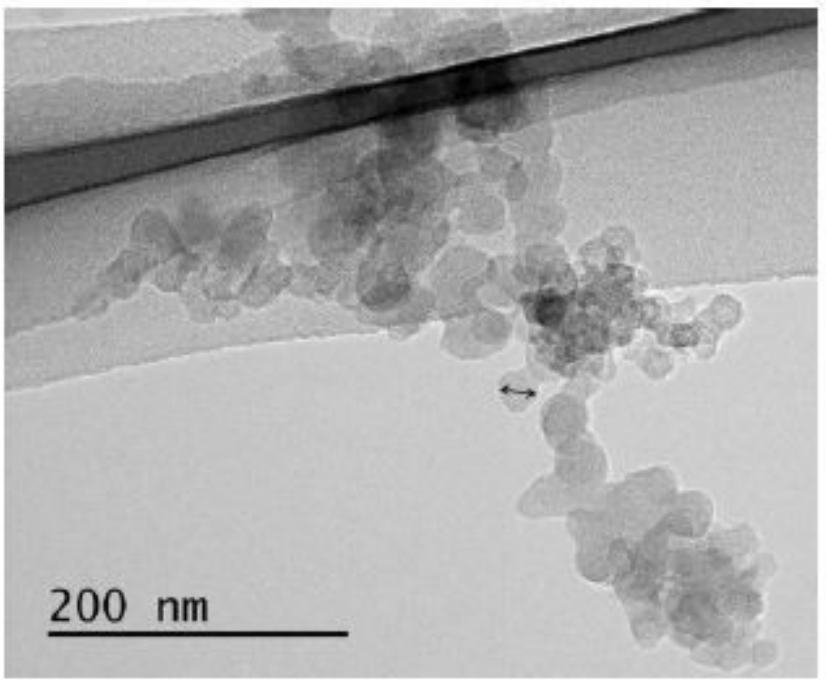

Figure 2

please see the manuscript file for the full caption 

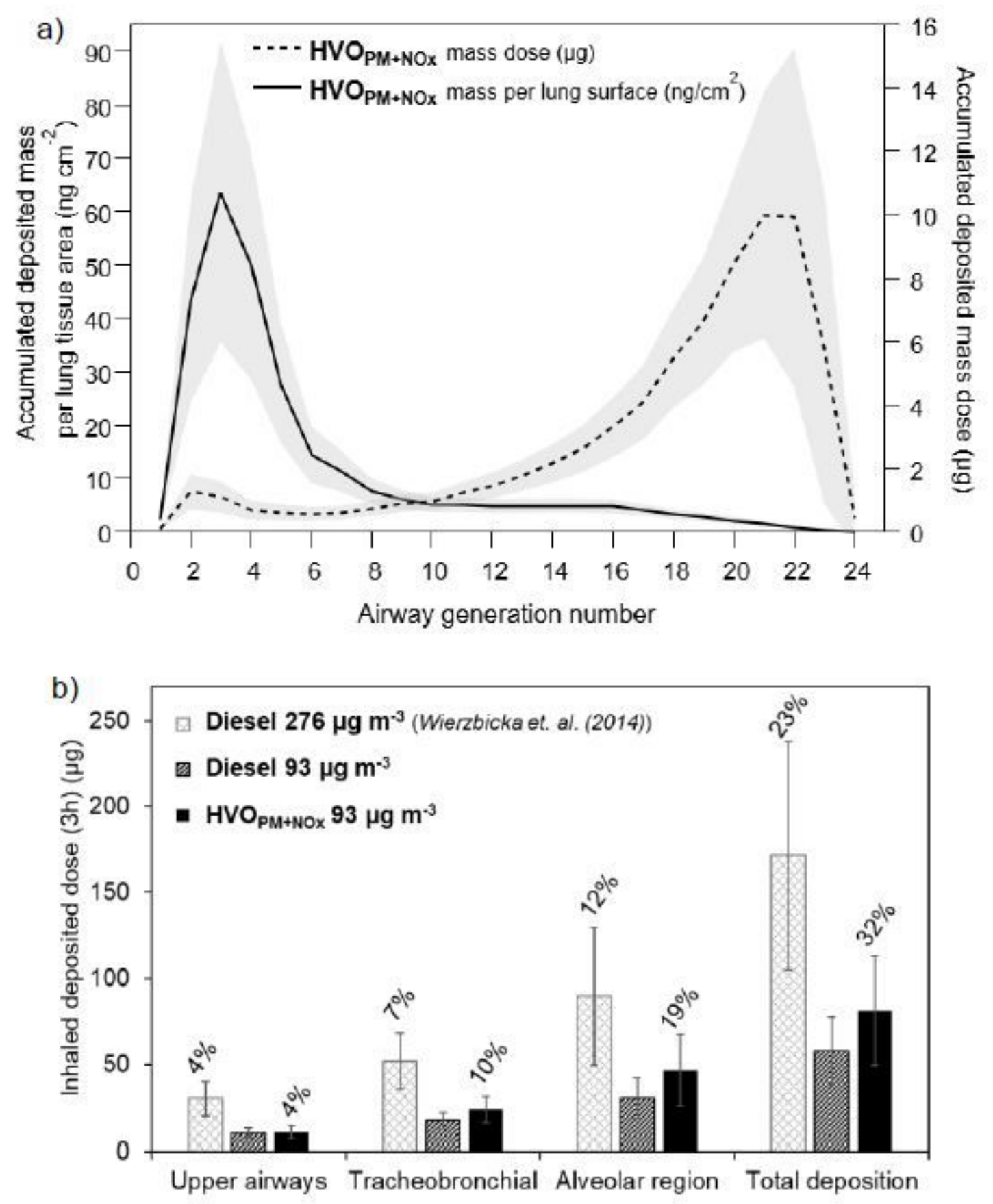

Figure 3

please see the manuscript file for the full caption 

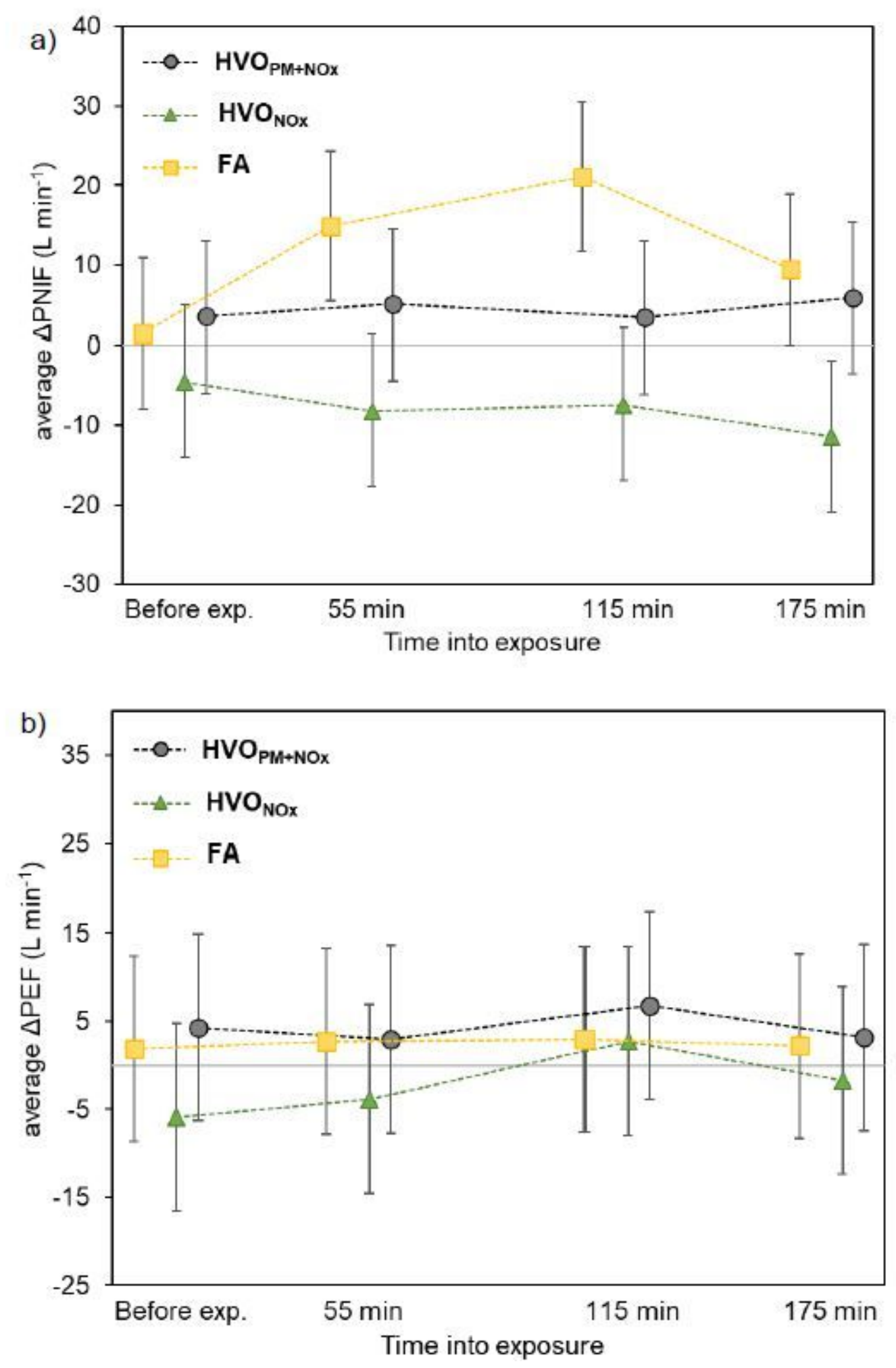

Figure 4

please see the manuscript file for the full caption

\section{Supplementary Files}

This is a list of supplementary files associated with this preprint. Click to download. 
- PFTGrenetalChamber2019Additionalfile1vF.pdf 